\title{
RESPUESTA POLÍTICA FRENTE A LAS ADVERSIDADES NATURALES EN EL SECTOR AGRÍCOLA DURANTE EL SIGLO XVIII
}

\author{
Jesús Manuel GonZÁlez BELTRÁN \\ Universidad de Cádiz
}

\begin{abstract}
Resumen
La incidencia de las adversidades naturales sobre el sector agrario, y la sociedad en su conjunto, es amplia y compleja. Se detectan consecuencias demográficas, sociales, económicas e, incluso, influencias en las actitudes mentales. Para atenuar los efectos negativos de estas situaciones de calamidad y crisis, las autoridades locales ponen en práctica una amplia gama de medidas correctoras. En este estudio se analiza la tipología de esas medidas, las dificultades de su ejecución y, en definitiva, la eficacia de las mismas.

Palabras clave: agricultura, adversidades naturales, ayuntamiento, trabajadores agrícolas, Jerez de la Frontera, siglo Xvill.
\end{abstract}

\begin{abstract}
The consequences of environmental adversities all over the agricultural sector, and the society in XVIIl century, is width and complex. We identify demographical, social, economical effects and, even influences on mental behaviour. Local authorities take a considerable number of countermeasures to diminish the negative impacts of those periods of crisis and calamities. On this essay, we categorize those measures, how difficult is its execution and, in definitive, its efficacy.

Key words: agriculture, calamities naturals, townhall, agricultural workers, Jerez de la Frontera, XVIII century.
\end{abstract}

\section{AGRICULTURA, ADVERSIDADES NATURALES Y PODERES PÚBLICOS}

La actividad agrícola, como ocurre en cualquier otro sector productivo, se ve condicionada, en su dinámica y en sus resultados, por toda una serie de factores y agentes, tanto internos como externos. En el caso de la agricultura podemos enumerar, sin ser exhaustivos, aspectos tales como la distribución de la propiedad de la tierra, las formas 
de acceso a su explotación, las relaciones de tipo laboral, la dependencia con respecto al mercado y el nivel de desarrollo técnico. Cuestiones que han constituido hasta la fecha la base de la mayoría de las monografías dedicadas al sector agrícola en la España Moderna'. Pero, a estos factores jurídicos, sociales y económicos hay que añadirle, en el caso de la agricultura, sobre todo por su influencia en los resultados finales de la producción, la gran repercusión de los denominados fenómenos naturales. En ellos se comprenden, principalmente, los agentes climatológicos, de forma especial cuando se manifiestan de forma extraordinaria, pero también otros elementos como las plagas de los cultivos, las epizootias de los animales de labor, los incendios forestales e, incluso, las enfermedades que afectan, fundamentalmente, a los trabajadores agrícolas.

En este trabajo pretendemos un acercamiento a estos factores naturales enumerados, con una doble finalidad. Por un lado, queremos conocer cual es su incidencia efectiva sobre el sector agrario, y, en concreto, sobre dos piezas fundamentales de su estructura: la producción y las relaciones de trabajo. Y, en segundo lugar, se analizará la acción política llevada a cabo por las autoridades, en especial por las municipales, con el objetivo de solventar, o al menos atenuar, las consecuencias negativas de los mencionados elementos naturales ${ }^{2}$.

El periodo temporal seleccionado es el que transcurre entre 1750 y 1799 . La segunda mitad del siglo XVII, es el momento álgido de la Ilustración o, mejor, de la afirmación del despotismo ilustrado como forma de gobernar, desarrollándose una política agraria de altos planteamientos, que se pueden seguir a través de las múltiples medidas legales puestas en vigor, aunque de resultados poco satisfactorios. A pesar de ello, lo cierto es que se va estableciendo un nuevo marco jurídico para regir gran parte de las relaciones agrarias, y a él deben atenerse las autoridades, y otros sectores sociales implicados, a la hora de tomar acuerdos y ejecutar decisiones ${ }^{3}$. Igualmente, la segunda parte de la centuria dieciochesca se caracteriza por un desarrollo demográfico que supone todo un reto para el escenario clásico de la agricultura y de su producción, especialmente cuando se repitan las situaciones de crisis de etapas anteriores.

El marco geográfico del estudio vendrá constituido por la importante ciudad bajoandaluza de Jerez de la Frontera. Se trata de una localidad de economía eminentemente agraria, de la que destaca su amplísimo término municipal, el tercero más

1. Sobre los temas de los estudios agrícolas podemos comparar lo que manifestó hace algunos años BERNAL. A. M.: «Las agriculturas de España en el siglo XVIIl», en Estructuras agrarias y reformismo ilustrado en la España del siglo XVIII, Madrid, 1989, pp. 11-24, con lo aportado, recientemente, por SAAVEDRA, Pegerto: «Trayectoria de la historiografia rural en la segunda mitad del siglo XX», en Balance de la historiografia modernista 1973-2001. Actas del VI Coloquio de Metodologia Histórica Aplicada, Santiago de Compostela, 2003, pp. 317-331.

2. En este aspecto seguimos la línea de investigación desarrollada, en varios artículos, por ALBEROLA Romá, A. Y, últimamente, en su monografia Catástrofe, economia y acción politica en la Valencia del siglo XVIII, Valencia, 1999.

3. Bernal, A. M.: La lucha por la tierra en la crisis del Antiguo Régimen, Madrid, 1970, p. 217, señala lo determinante que fue el periodo de 1760-1845 en la «configuración de la estructura social y económica» del mundo rural. 
extenso de España, con $1.416 \mathrm{Km}^{2}$, en el que se comprenden marismas, campiñas y sierras, lo que facilita una diversidad de usos agrícolas y ganaderos, por otra parte, plenamente coordinados. Así, el cultivo predominante del cereal precisa una crecida cabaña ganadera, de bueyes y yeguas, para las faenas del campo. La elevada población, el censo de Floridablanca (1787) da la cifra de 45.506 habitantes, y el hecho de que, de $\operatorname{los} 13.597$ individuos que son considerados como población activa, hasta 7.752 , el $57 \%$, se computen como jornaleros agrícolas ${ }^{4}$, son también elementos a tener muy en cuenta en la selección de Jerez de la Frontera. Por último, la cercanía a la ciudad de Cádiz y su bahía posibilitan, a los productores y especuladores agrícolas, el aliciente de una facilidad para la venta de los excedentes $y$, por otra parte, para las autoridades jerezanas la perspectiva de obtener, de forma más factible y barata, recursos alimentarios en épocas de carestía 5 .

Para el desarrollo del estudio se han tomado y analizados tres tipos de fuentes documentales básicas. Por un lado, tenemos los datos de los diezmos, en concreto los referidos al conjunto del arzobispado de Sevilla y los de las localidades de Jerez de la Frontera, Trebujena, Medina Sidonia y El Puerto de Santa Maríá. Sabemos la importancia que para el conocimiento de la producción cerealística tienen las series del diezmo ${ }^{7}$, pero también los problemas de fiabilidad que conllevan debido a aspectos tan variados tales como la forma de recaudar los diezmos, directa por los partícipes o mediante arrendamiento, o las posibles resistencias a su pago, bien por coyunturas desfavorables o bien por situaciones claras de fraude ${ }^{8}$. Como nuestra intención no es tanto el conocer exactamente la producción real de los cereales como poder apreciar las teóricas oscilaciones de las cosechas, los problemas reseñados no desvirtúan el uso de las series diezmales ni las conclusiones a las que podamos llegar.

4. Datos del Censo de 1787 «Floridablanca», Cádiz, Madrid, 1986.

5. Estos aspectos sobre Jerez de la Frontera se pueden ampliar en GonZÁlez Beltrán, J. M. y PereirA, J. L.: «Jerez de la Frontera en la Edad Moderna», en CARO, D.: Historia de Jerez de la Frontera, Tomo 2 , El Jerez moderno y contemporáneo, Cádiz, 1999, pp. 13-194.

6. Los datos diezmales correspondientes a pan terciado del arzobispado sevillano y de Jerez de la Frontera, y a tercias de cereales de Medina Sidonia y Trebujena se los debemos a Ponsot, P.: Atlas de Historia Económica de la Baja Andalucía (siglos XVI-XIX), Granada, 1986, pp. 236-237, 335, 354 y 422. Los de El Puerto en base a la información aportada por IGLESIAS, J. J.: Una ciudad mercantil en el siglo XVIII: El Puerto de Santa Maria, Sevilla, 1991, pp. 107-108.

7. Sobre ello, GOY, J. y LE ROY LADURIE, E.: Les fluctuations du produit de la dime. Conjoncture décimale et domaniale de la fin du Moyen Age au XVIlle siécle, París-La Haya, 1972; o EIRAS, A.: «Evolución del producto decimal en Galicia a finales del Antiguo Régimen: las primeras series diezmales», en Actas de las I Jornadas de Metodología Aplicada de las Ciencias Sociales. Metodologia de la Historia Moderna. Economia y demografia, Santiago de Compostela, 1975, pp. 51-90.

8. Aspectos señalados por MARCos MARTiN, A.: «De nuevo sobre los diezmos. La documentación decimal de la diócesis de Palencia: problemas que plantea», Investigaciones Históricas, 4 (1983), pp. 101-122; ARDIT LUCAS, M.: «Recaudación y fraude diezmal en el siglo XVIII valenciano», en Estructuras agrarias y reformismo..., pp. 391-410; y CANALES, E.: «Los diezmos en su etapa final», en La economía española al final del Antiguo Régimen, I, Agricultura, Madrid, 1982, pp. 103-187. 
La segunda fuente documental serian los registros parroquiales, en concreto los datos sobre bautizos, defunciones y matrimonios que están anotados en los libros sacramentales de las ocho parroquias en que se distribuye la feligresía de Jerez de la Frontera". Esta información demográfica nos permitirá advertir las relaciones existentes entre las cosechas, buenas o escasas, y los movimientos de la población jerezana.

Por último, el tercer tipo de fuente que vamos a utilizar esta conformado por la documentación municipal, preferentemente actas capitulares, pero siempre complementadas con material adicional en el que se incluyen informes, normativa, autos de ejecución de acuerdos, etc.. Estos documentos nos reseñaran no sólo la existencia y persistencia de los fenómenos naturales, sino también la problemática generada por los mismos en el sector agrario, así como la respuesta que a las situaciones de crisis planteadas dan las autoridades del gobierno local.

En las siguientes páginas, veremos, en primer lugar, la incidencia de los distintos fenómenos naturales que se dieron en Jerez de la Frontera durante la segunda mitad del siglo XVIII. Para, a continuación, analizar la respuesta gubernamental, en su triple dimensión: religiosa, económica y de orden público.

\section{LA ACCIÓN DE LOS FENÓMENOS NATURALES}

Como ya hemos indicado, el desarrollo de la actividad agrícola se ve muy determinado por la incidencia de los llamados agentes o fenómenos naturales, que no son exclusivamente los climatológicos, aunque éstos sean los más conocidos, sino que también debemos incluir otros elementos como las plagas, los incendios y las enfermedades de animales y hombres. Los efectos de estos agentes naturales son muy amplios sobre el sector agrícola. Casi siempre se incide en el aspecto de la producción, mayor o menor en proporción a los rigores de los fenómenos naturales. Pero la influencia va más allá, y repercute sobre otras cuestiones como la renta, tanto la que percibe el agricultor directo como la que es capaz de drenar del productor un amplio grupo social de perceptores indirectos (arrendadores, diezmeros, prestamistas, recaudadores de impuestos). Del mismo modo, las consecuencias de estos agentes naturales afectan a las relaciones de trabajo, bien por la imposibilidad de realizar las tareas agrícolas debido, por ejemplo, a una climatología adversa, o bien por la insuficiencia de jornaleros motivada por la acción de una epidemia. Y todo ello, siendo restrictivo en el planteamiento, ya que en una sociedad básicamente agraria y que depende del producto agrícola para subsistir, las negativas repercusiones de los fenómenos naturales sobre el sector agrario provocan directas secuelas sobre el conjunto de la sociedad.

A continuación, vamos a presentar cual fue el panorama de adversidades naturales que afectó a la localidad de Jerez de la Frontera durante la segunda mitad del siglo XVIII, para lo cual contamos con el Cuadro I, y pasaremos posteriormente a valorar sus contrarios efectos.

9. Esta información queda recogida en un trabajo más amplio realizado por BUSTOS RoDRiGUEZ, M. y otros: «La población de la provincia de Cádiz en los siglos XVIl y XVIIl», Trocadero. Revista de historia Moderna y Contemporínea, 2 (1990), pp. 5-72. 


\section{Cuadro I}

Adversidades sufridas por el campo de Jerez de la Frontera en la segunda mitad del siglo XVIII

\begin{tabular}{|c|c|c|}
\hline FECHA & ADVERSIDAD & COMENTARIOS \\
\hline $3-3-1750$ & Sequía. & $\begin{array}{l}\text { La situación se mantenía a 1-4-1750. Muerte de } \\
\text { potros. }\end{array}$ \\
\hline $6-6-1753$ & Sequía. & Los granos sembrados no llegaron a nacer. \\
\hline $3-5-1755$ & Plaga de langosta. & Casi extinguida el 16-5-1755. \\
\hline $28-3-1757$ & Sequía. & Falta de ganado. \\
\hline $20-4-1757$ & Plaga de langosta. & Procesión con cabeza San Gregorio Ostiense. \\
\hline $2-6-1760$ & $\begin{array}{l}\text { Epidemia de } \\
\text { tercianas. }\end{array}$ & Moderada. \\
\hline $3-2-1763$ & $\begin{array}{l}\text { Abundancia de } \\
\text { lluvias. }\end{array}$ & Falta de trabajo. \\
\hline $22-4-1763$ & Sequía. & Falta de granos que continúa el 19-5-1763. \\
\hline $14-4-1764$ & Sequía. & Falta de trabajo y precio alto del trigo. \\
\hline $16-3-1772$ & $\begin{array}{l}\text { Abundancia de } \\
\text { lluvias. }\end{array}$ & Falta de trabajo. \\
\hline $24-4-1773$ & Sequía. & Falta de trigo. \\
\hline $24-4-1773$ & Plaga de orugas. & Continúa en mayo. \\
\hline 1773 & Incendio. & Pérdida de arbolado. \\
\hline $1-9-1776$ & Pedrisco. & Pérdida cosecha de uva. \\
\hline $26-1-1778$ & $\begin{array}{l}\text { Abundancia de } \\
\text { lluvias. }\end{array}$ & $\begin{array}{l}\text { Desde 15-12-1777. Se pierden las cosechas de } \\
\text { trigo y uva. }\end{array}$ \\
\hline $14-11-1779$ & Sequía. & Muerte de ganado equino. \\
\hline $17-1-1780$ & $\begin{array}{l}\text { Abundancia de } \\
\text { lluvias. }\end{array}$ & Falta de trabajo. \\
\hline $12-4-1780$ & Sequía. & Alto precio de los granos. \\
\hline $9-3-1781$ & Sequía. & Sembrados en peligro. \\
\hline 24-4-1781 & Plaga de langosta. & Concluida el 19-5-1781. \\
\hline $12-11-1781$ & Sequía. & Imposibilidad de sembrar. \\
\hline $8-2-1782$ & Plaga de langosta. & Es leve, continúa el 24-4-1782. \\
\hline $1-9-1782$ & Sequía. & Pérdida cosechas de uva y bellotas. \\
\hline 1782 & Incendio. & Pérdida de arbolado. \\
\hline $28-10-1784$ & $\begin{array}{l}\text { Epidemia de } \\
\text { tercianas. }\end{array}$ & Es la fecha de su conclusión. \\
\hline $7-1-1785$ & $\begin{array}{l}\text { Abundancia de } \\
\text { lluvias. }\end{array}$ & $\begin{array}{l}\text { Se prolongan hasta 5-4-1785. Falta de trabajo. } \\
\text { Precios altos granos. }\end{array}$ \\
\hline
\end{tabular}




\begin{tabular}{|l|l|l|}
\hline \multicolumn{1}{|c|}{ FECHA } & \multicolumn{1}{|c|}{ ADVERSIDAD } & \multicolumn{1}{c|}{ COMENTARIOS } \\
\hline 17-10-1785 & $\begin{array}{l}\text { Epidemia de } \\
\text { tercianas. }\end{array}$ & Alta mortalidad. \\
\hline $20-3-1786$ & $\begin{array}{l}\text { Abundancia de } \\
\text { lluvias. }\end{array}$ & Falta de trabajo. \\
\hline $20-3-1786$ & $\begin{array}{l}\text { Epidemia de } \\
\text { tercianas. }\end{array}$ & $\begin{array}{l}\text { Llega a enero de 1787. Falta de trabajadores, } \\
\text { tierras sin labrar. }\end{array}$ \\
\hline $5-3-1790$ & Sequía. & Llueve el 22-3-1790. \\
\hline $24-3-1791$ & Sequía. & Llueve el 30-4-1791. \\
\hline $27-1-1792$ & $\begin{array}{l}\text { Abundancia de } \\
\text { lluvias. }\end{array}$ & Falta de trabajo. \\
\hline $2-1-1793$ & Sequía y heladas. & $\begin{array}{l}\text { La falta de lluvia se prolonga hasta el mes de } \\
\text { mayo. Carestía y alto precio de los granos. }\end{array}$ \\
\hline $1-4-1795$ & Plaga de langosta. & Poca incidencia. \\
\hline $1-3-1796$ & Plaga de langosta. & Poca incidencia. \\
\hline $30-12-1796$ & $\begin{array}{l}\text { Abundancia de } \\
\text { lluvias. }\end{array}$ & Retraso en la siembra. \\
\hline
\end{tabular}

De los 50 años estudiados, hasta en 24 de ellos, un $48 \%$, se produce una adversidad lo suficientemente destacada como para quedar registrada en la documentación, siendo en total 36 las incidencias reseñadas, ya que, en algunas anualidades la presencia de elementos naturales negativos fue doble o triple. De los 36 eventos recogidos, la mayoría corresponden a fenómenos climáticos, en concreto 23 , que se producen en 20 años, es decir, en un $40 \%$ de los que componen el periodo analizado. En 6 años tenemos la presencia de plagas de langosta, a los que añadimos un año con plaga de orugas en las arboledas de bellota. Los incendios, que debían ser abundantes, sólo son mencionados en dos ocasiones. Por último, las epidemias de tercianas se manifiestan con preocupación en cuatro años. Vamos a ver, más detenidamente, cada cuestión por separado.

En primer lugar, un análisis de las adversidades climáticas. Existe un consenso general sobre la significación del clima para la actividad agrícola, y por lo tanto sobre la precisión y necesidad de su estudio. No obstante nos encontramos con un problema metodológico, carecemos de mediciones científicas sobre los agentes meteorológicos con anterioridad al siglo XIX, por lo que resulta difícil seguir no sólo la evolución general del clima sino su incidencia cotidiana ${ }^{10}$. Para paliar este vacío, surgió en la década de 1960 la paleoclimatología, ciencia que estudia el clima del pasado y pretende obtener las características climáticas de un determinado espacio, amplio o reducido, durante un

10. Esta carencia ya señalada por Domínguez ORTIZ, A.: Sociedad y Estado en el siglo XVIII español, Barcelona, 1976, p. 406, y reiterada en El Antiguo Régimen: los Reyes Católicos y los Austrias, Madrid, 1988, p. 193. 
tiempo histórico concreto. La falta de mediciones científica, tal como ya apuntábamos, obliga a utilizar otro tipo de información, en general fuentes documentales de diversa procedencia (actas municipales y eclesiásticas, expedientes agrarios, contabilidades privadas, correspondencia, etc.) que contienen datos indirectos referentes al clima, tales como noticias sobre sequías, inundaciones, temporales, nevadas y otros meteoros que se han manifestado, casi siempre, de forma extraordinaria. Una especialidad de la paleoclimatolía, la climatología histórica es la que se dedica, mediante el análisis de estas fuentes documentales, a la obtención de las pertinentes referencias sobre el clima en épocas pasadas"

Utilizando los métodos de la climatología histórica en conjunción con otros propios de la investigación histórica, algunos historiadores también han hecho sus aportaciones sobre el clima del pasado y sus repercusiones sobre la sociedad en general y agraria en particular ${ }^{12}$. La conclusión a la que llegan estos estudios es que la agricultura española del siglo XVIIl, heredera y continuadora de las prácticas de las centurias anteriores, con nulos avances técnicos y sin la utilización sistemática de abonos, dependía de una climatología óptima, que escapa a la capacidad de control campesino, para producir unas cosechas satisfactorias que permitieran, sin estrecheces, abastecer a la población. Pero, esa climatología no era siempre equilibrada y homogénea, lo que se traduce en fuertes oscilaciones de la producción y, en consonancia, en la manifestación de un doble fenómeno alternativo: la generación de excedentes o, lo que tenía mayores repercusiones, cosechas deficitarias. Para comprobar estas fluctuaciones tan sólo es necesario observar los gráficos que, basados de forma mayoritaria en las series de diezmos, nos aportan las monografías dedicadas al estudio del producto agrario ${ }^{13}$.

11. Las pautas metodológicas, sobre todo en lo que a la selección y tratamiento de las fuentes documentales se refiere, las encontramos en LE ROY LADURIE, E.: Historia del clima desde el año mil, México, 1990 (la primera edición francesa en París, 1967). En España contamos con los trabajos, aún inéditos, de J. M. FonTANA TARRATS, realizados entre 1971-1978 (los ejemplares mecanografiados en la biblioteca del INM); y los más recientes de FonT TulLot, I.: Historia del clima de España. Cambios climáticos y sus causas, Madrid, 1988; BARRIEndos Vallvé, M.: «El clima histórico de Catalunya (siglos XIV-XIX). Fuentes, métodos y primeros resultados》, Revista de Geografia, XXX-XXXI (1996-1997), pp. 69-96; y ZAMORA PASTOR, R.: El final de la pequeña edad de hielo en Alicante, Alicante, 2002.

12. En esta línea de investigación, tenemos los trabajos de Álvarez VÁzquez, J. A.: Sequias y lluvias en la provincia de Zamora en los siglos XVII, XVIII y XIX, Madrid, 1986; DiAZ-PINTADO, I.: «Climatología de la Mancha durante el siglo Xvill», Cuadernos de Historia Moderna, 12 (1991), pp. 123-166; ALBEROLA ROMÁ, A.: «La percepción de la catástrofe: sequia e inundaciones en tierras valencianas durante la primera mitad del siglo XVIII〉, Revista de Historia Moderna. Anales de la Universidad de Alicante, 15 (1996), pp. 257-269.

13. Algunos ejemplos significativos nos lo aportan ANES, G.: Las crisis agrarias en la España Moderna, Madrid, 1970; Garcia SANZ, A.: Desarrollo y crisis del Antiguo Régimen en Castilla la Vieja. Economía $y$ sociedad en tierras de Segovia de 1500 a 1814, Madrid, 1977; PONSOT, P.: «En Andalousie Occidentale: les fluctuations de la productions du ble sous l'Ancien Regime), en Etudes Rurales, 34 (1969), pp. 72 112; BARREIRO, B.: «La producción agrícola de Xallas a través de los arrendamientos diezmales: intento de aproximación", en Actas de las I Jornadas de Metodología.., III, pp. 91-108. 
Veamos, con relación a lo dicho, que ocurre en la zona de Jerez de la Frontera, para lo cual contamos con el cuadro II. En él, ofrecemos para el periodo cronológico de 1750-1799, basándonos en los datos diezmales ofrecidos por Ponsot, como fueron las cosechas en Jerez; en las localidades colindantes de Trebujena, EI Puerto de Santa María y Medina Sidonia; así como en el conjunto del arzobispado hispalense, al que pertenece la mayor parte del término jerezano y que incluye las provincias de Sevilla, Huelva y parte de Cádiz. Del mismo modo, aportamos la teórica cosecha media obtenida de las cinco series mencionadas. La inclusión de los datos de otros ámbitos geográficos, aunque cercanos a Jerez, tiene como fin el detectar tanto la especificidad de la localidad jerezana como las posibles correspondencias que nos permitieran hablar de tendencias climáticas concretas para un espacio geográfico no exclusivamente local. En esta línea, también utilizaremos, aunque puntualmente, información sobre el clima de otras zonas de la península ibérica.

Las cosechas han sido clasificadas en 6 tipos: $\mathrm{N}+$ y N-cuando oscilan entre la media y un $25 \%$ arriba o abajo, son las consideradas normales; B y $\mathrm{M}$ cuando la desviación de la media se mueve entre el 26 y el $50 \%$ de más o menos, son cosechas buenas o malas; y MB y MM cuando se supera e1 $51 \%$ sobre la media de forma positiva o negativa, nos encontramos con recolecciones excelentes o catastróficas.

Cuadro II

Resultado de las cosechas en la zona jerezana

\begin{tabular}{|c|c|c|c|c|c|c|}
\hline AÑO & JEREZ & ARZOBISPADO & TREBUIENA & EL PUERTO & MEDINA & MEDIA \\
\hline 1750 & - & $\mathrm{M}$ & $\mathrm{MM}$ & $\mathrm{MM}$ & $\mathrm{MM}$ & $\mathrm{MM}$ \\
\hline 1751 & - & $\mathrm{MB}$ & $\mathrm{N}+$ & $\mathrm{N}-$ & $\mathrm{N}-$ & $\mathrm{N}+$ \\
\hline 1752 & - & $\mathrm{MB}$ & $\mathrm{MB}$ & $\mathrm{B}$ & $\mathrm{N}+$ & $\mathrm{MB}$ \\
\hline 1753 & $\mathrm{MM}$ & $\mathrm{MM}$ & $\mathrm{MM}$ & $\mathrm{MM}$ & $\mathrm{M}$ & $\mathrm{MM}$ \\
\hline 1754 & $\mathrm{MB}$ & $\mathrm{B}$ & $\mathrm{MB}$ & $\mathrm{MB}$ & $\mathrm{MM}$ & $\mathrm{B}$ \\
\hline 1755 & $\mathrm{~B}$ & $\mathrm{~B}$ & $\mathrm{MB}$ & $\mathrm{MB}$ & $\mathrm{MB}$ & $\mathrm{MB}$ \\
\hline 1756 & $\mathrm{~N}+$ & $\mathrm{N}-$ & $\mathrm{B}$ & $\mathrm{N}+$ & $\mathrm{MB}$ & $\mathrm{B}$ \\
\hline 1757 & $\mathrm{~B}$ & $\mathrm{~N}-$ & $\mathrm{N}-$ & $\mathrm{M}$ & $\mathrm{N}-$ & $\mathrm{N}-$ \\
\hline 1758 & $\mathrm{~N}+$ & $\mathrm{N}-$ & $\mathrm{M}$ & $\mathrm{N}-$ & $\mathrm{N}+$ & $\mathrm{N}-$ \\
\hline 1759 & $\mathrm{~B}$ & $\mathrm{~N}-$ & $\mathrm{M}$ & $\mathrm{N}-$ & $\mathrm{B}$ & $\mathrm{N}-$ \\
\hline 1760 & $\mathrm{~N}+$ & $\mathrm{M}$ & $\mathrm{N}-$ & $\mathrm{N}-$ & $\mathrm{N}-$ & $\mathrm{N}-$ \\
\hline 1761 & $\mathrm{~B}$ & $\mathrm{~N}-$ & $\mathrm{B}$ & $\mathrm{N}-$ & $\mathrm{MB}$ & $\mathrm{N}+$ \\
\hline 1762 & $\mathrm{~N}-$ & $\mathrm{M}$ & $\mathrm{M}$ & $\mathrm{N}-$ & $\mathrm{N}+$ & $\mathrm{N}-$ \\
\hline 1763 & $\mathrm{MM}$ & $\mathrm{M}$ & $\mathrm{N}-$ & $\mathrm{M}$ & $\mathrm{M}$ & $\mathrm{M}$ \\
\hline 1764 & $\mathrm{~N}+$ & $\mathrm{N}-$ & $\mathrm{N}+$ & $\mathrm{B}$ & $\mathrm{N}+$ & $\mathrm{N}+$ \\
\hline 1765 & $\mathrm{M}$ & $\mathrm{MM}$ & $\mathrm{M}$ & $\mathrm{M}$ & $\mathrm{N}-$ & $\mathrm{M}$ \\
\hline 1766 & $\mathrm{~B}$ & $\mathrm{~N}+$ & $\mathrm{MB}$ & $\mathrm{MB}$ & $\mathrm{B}$ & $\mathrm{MB}$ \\
\hline 1767 & $\mathrm{MM}$ & $\mathrm{MM}$ & $\mathrm{MM}$ & $\mathrm{MM}$ & $\mathrm{M}$ & $\mathrm{MM}$ \\
\hline 1768 & $\mathrm{M}$ & $\mathrm{M}$ & $\mathrm{M}$ & $\mathrm{N}-$ & $\mathrm{M}$ & $\mathrm{M}$ \\
\hline
\end{tabular}




\begin{tabular}{|c|c|c|c|c|c|c|}
\hline A ̃̃o & JEREZ & ARZOBISPADO & TREBUJENA & EL PUERTO & MEDINA & MEDIA \\
\hline 1769 & $\mathrm{~N}+$ & $\mathrm{N}-$ & $\mathrm{N}+$ & MB & $\mathrm{N}-$ & $\mathrm{N}+$ \\
\hline 1770 & $\mathrm{~N}-$ & $\mathrm{N}+$ & $\mathrm{MB}$ & $\mathrm{MB}$ & $\mathrm{N}+$ & $\mathrm{B}$ \\
\hline 1771 & $\mathrm{~N}-$ & $\mathrm{N}-$ & $\mathrm{N}-$ & $\mathrm{N}+$ & $\mathrm{M}$ & $\mathrm{N}-$ \\
\hline 1772 & $\mathrm{M}$ & M & $\mathrm{N}-$ & $\mathrm{N}+$ & M & M \\
\hline 1773 & $\mathrm{M}$ & $\mathrm{N}-$ & $\mathrm{B}$ & $\mathrm{M}$ & $\mathrm{N}-$ & $\mathrm{N}-$ \\
\hline 1774 & $\mathrm{~N}-$ & $\mathrm{N}+$ & $\mathrm{N}-$ & $\mathrm{N}+$ & $\mathrm{N}+$ & $\mathrm{N}+$ \\
\hline 1775 & $\mathrm{~B}$ & $\mathrm{~N}+$ & $\mathrm{N}+$ & $\mathrm{N}-$ & MB & $\mathrm{B}$ \\
\hline 1776 & N- & $\mathrm{N}-$ & $\mathrm{N}-$ & $\mathrm{N}$ & $\mathrm{N}-$ & $\mathrm{N}-$ \\
\hline 1777 & $\mathrm{~N}+$ & $\mathrm{N}+$ & $\mathrm{M}$ & $\mathrm{N}+$ & $\mathrm{M}$ & $\mathrm{N}-$ \\
\hline 1778 & $\mathrm{~N}-$ & $\mathrm{N}+$ & $\mathrm{N}-$ & MM & $\mathrm{M}$ & $\mathrm{M}$ \\
\hline 1779 & $\mathrm{~N}+$ & $\mathrm{N}-$ & $\mathrm{N}+$ & $\mathrm{N}-$ & $\mathrm{N}-$ & $\mathrm{N}-$ \\
\hline 1780 & $B$ & $\mathrm{~N}+$ & $\mathrm{N}+$ & $\mathrm{N}-$ & $\mathrm{N}-$ & $\mathrm{N}+$ \\
\hline 1781 & $\mathrm{~B}$ & $\mathrm{~B}$ & $\mathrm{~N}-$ & $\mathrm{N}+$ & $\mathrm{MB}$ & $\mathrm{B}$ \\
\hline 1782 & $\mathrm{MB}$ & $\mathrm{MB}$ & $\mathrm{B}$ & $\mathrm{B}$ & $\mathrm{MB}$ & $\mathrm{MB}$ \\
\hline 1783 & $\mathrm{~N}-$ & $\mathrm{N}+$ & $\mathrm{N}-$ & $\mathrm{N}+$ & MB & $\mathrm{N}+$ \\
\hline 1784 & $\mathrm{MM}$ & $\mathrm{MM}$ & $\mathrm{MM}$ & $\mathrm{MM}$ & $\mathrm{MM}$ & MM \\
\hline 1785 & N- & $\mathrm{N}+$ & $\mathrm{N}-$ & $\mathrm{MM}$ & MM & M \\
\hline 1786 & $\mathrm{~N}-$ & $\mathrm{N}$ & $\mathrm{M}$ & $\mathrm{MM}$ & $\mathrm{MM}$ & $\mathrm{M}$ \\
\hline 1787 & $\mathrm{M}$ & $\mathrm{M}$ & $\mathrm{N}-$ & $\mathrm{MM}$ & $\mathrm{MM}$ & $\mathrm{MM}$ \\
\hline 1788 & $\mathrm{~N}+$ & $\mathrm{N}+$ & $\mathrm{B}$ & $\mathrm{N}+$ & $\mathrm{M}$ & $\mathrm{N}+$ \\
\hline 1789 & $\mathrm{~N}-$ & $\mathrm{N}+$ & $\mathrm{N}-$ & $\mathrm{N}-$ & $\mathrm{N}+$ & $\mathrm{N}-$ \\
\hline 1790 & $\mathrm{MB}$ & $\mathrm{B}$ & $\mathrm{MB}$ & $\mathrm{MB}$ & $\mathrm{B}$ & MB \\
\hline 1791 & $\mathrm{~N}+$ & $\mathrm{N}-$ & $\mathrm{M}$ & $\mathrm{M}$ & $\mathrm{N}+$ & $\mathrm{N}-$ \\
\hline 1792 & $\mathrm{~N}-$ & $\mathrm{N}-$ & $\mathrm{N}-$ & $\mathrm{M}$ & $\mathrm{N}-$ & $\mathrm{M}$ \\
\hline 1793 & $\mathrm{MM}$ & $\mathrm{M}$ & $\mathrm{MM}$ & $\mathrm{MM}$ & $\mathrm{B}$ & $\mathrm{M}$ \\
\hline 1794 & $\mathrm{~N}+$ & - & MB & $\mathrm{MB}$ & $\mathrm{N}+$ & B \\
\hline 1795 & $\mathrm{~N}-$ & - & $\mathrm{N}+$ & N- & $\mathrm{N}-$ & $\mathrm{N}-$ \\
\hline 1796 & $\mathrm{~N}-$ & - & $\mathrm{M}$ & $\mathrm{N}-$ & $\mathrm{N}-$ & $M$ \\
\hline 1797 & $\mathrm{~N}-$ & - & $\mathrm{N}-$ & $\mathrm{N}-$ & $\mathrm{N}$ & $\mathrm{N}-$ \\
\hline 1798 & $\mathrm{~B}$ & - & $\mathrm{MB}$ & $\mathrm{MB}$ & $\mathrm{MB}$ & MB \\
\hline 1799 & $\mathrm{~N}-$ & - & $\mathrm{N}+$ & $\mathrm{N}+$ & $\mathrm{M}$ & $\mathrm{N}-$ \\
\hline Resumen & $\begin{array}{l}3 \mathrm{MB} \\
9 \mathrm{~B} \\
10 \mathrm{N+} \\
15 \mathrm{~N}- \\
5 \mathrm{M} ; \\
5 \mathrm{MM}\end{array}$ & $\begin{array}{l}3 \mathrm{MB} ; 4 \mathrm{~B} \\
10 \mathrm{~N}+15 \mathrm{~N}- \\
8 \mathrm{M} ; 4 \mathrm{MM}\end{array}$ & $\begin{array}{l}8 \mathrm{MB} ; 5 \mathrm{~B} \\
8 \mathrm{~N}+15 \mathrm{~N}-; \\
9 \mathrm{M} ; 5 \mathrm{MM}\end{array}$ & $\begin{array}{l}8 \mathrm{MB} ; 3 \mathrm{~B} \\
9 \mathrm{N+} ; \\
15 \mathrm{~N}- \\
6 \mathrm{M} ; \\
9 \mathrm{MM}\end{array}$ & $\begin{array}{l}8 \mathrm{MB} ; 4 \mathrm{~B} \\
9 \mathrm{Nt} \\
13 \mathrm{~N}- \\
10 \mathrm{M} ; \\
6 \mathrm{MM}\end{array}$ & $\begin{array}{l}6 \mathrm{MB} \\
6 \mathrm{~B} ; \\
8 \mathrm{NH} ; \\
15 \mathrm{~N}-; \\
10 \mathrm{M} ; \\
5 \mathrm{MM}\end{array}$ \\
\hline
\end{tabular}

MB: Muy Buena; B: Buena; N-t: Normal alta; N-: Normal baja; M: Mala; MM: Muy Mala. 
El análisis del cuadro II nos permite comentar varias cuestiones. En primer lugar, la cierta homogeneidad que exhiben las fluctuaciones de las cosechas en las cinco series, lo que equivale a hablar de la zona de la Baja Andalucía como de un espacio de producción cerealística con características comunes. En concreto contamos con 37 años, un $74 \%$ de los del periodo, en los que todas las series, o todas menos una, presentan, aunque pueda variar la intensidad, la misma tendencia, ya sea positiva o negativa, de las cosechas. Por supuesto, se da una cierta especificidad en cada una de las localidades, pero el margen es bastante reducido. Por ejemplo, en Jerez, son sólo diez las cosechas, el $20 \%$, que marcan una dirección contraria a la señalada por las otras series del estudio.

Segunda, se hace patente la relación directa de las fluctuaciones de la producción con las condiciones climáticas de cada año. La mayoría de las recolecciones deficitarias que se dan en Jerez ocurren en años en los que la documentación hace referencia a la aparición de fenómenos meteorológicos extraordinarios, aquellos que recopilábamos en el Cuadro I. Así, las malas y catastróficas cosechas de 1750, 1753, 1763, 1773 y 1793 coinciden con años en los que la primavera fue muy seca. Por otro lado, la mala recolección de 1772 y las normales, aunque cortas, de 1778, 1785, 1786, 1792 y 1797, están en relación con la abundancia de lluvias y su persistencia tras el periodo invernal ${ }^{14}$.

Los datos parecen confirmar como principal problema de la agricultura cerealística de Jerez el de la necesidad de agua. En 1780 la Sociedad Económica de Amigos del País de Sevilla remitía al ayuntamiento de Jerez un informe, redactado por un socio jerezano, en el que se exponían algunos de los problemas de la localidad. Con respecto a la agricultura se señalaba que «las tierras de labor son muy fuertes y escaseando las aguas se pierden las mieses», por lo que se proponía la apertura de acequias de riego aprovechando el caudal del río Guadalete ${ }^{15}$. No se puede hablar de una pluviosidad concreta para todo el término de Jerez, ya que la amplitud del mismo introduce múltiples matices. En la parte de la campiña, la que predominantemente alberga el cultivo de cereal, se contabilizan de media 693 litros al año, estando la moda entre los $600 \mathrm{y}$ 700 litros $^{16}$. No es una pluviosidad alta, pero si suficiente si llueve en los tiempos oportunos. Así, es determinante algo de lluvia en la primavera, entre mediados de marzo y principios de mayo, puesto que «al no disponer las plantas cereales de la humedad que en tan critica época les es absolutamente precisa, se desarrollan poco y granan mal",, en definitiva, la falta de lluvia en estos meses «es lo que comínmente ocasiona las

14. En la Mancha, salvo 1763, los demás años de sequía coinciden. Como años lluviosos tenemos los de 1772, 1785, 1786 y 1797. DíAs-PINTADO, J.: Art. Cit., pp. 130-135

15. Carta e informe en Archivo Municipal de Jerez de la Frontera (A.M.J.F.), Actas de cabildo (A.C.), cabildo de 28-2-1780, ff. 40 y 365 .

16. Entre junio y septiembre apenas caen 25 litros de agua. El fenómeno de la torrencialidad no es muy corriente, aunque, eso sí, la mayoría de la lluvia se concentra en unos pocos temporales invernales. Datos ofrecidos por Mapas provinciales de suelos, Cádiz, 1991, p. 97. 
mermas en la producción y en ocasiones la pérdida de las cosechas» ${ }^{17}$. En este sentido, resulta sintomático que de las 14 alusiones a la carencia de lluvias, con tintes de sequía, reseñadas, entre 1750 y 1799 en las actas del cabildo jerezano, hasta 9 se concentren en los meses de marzo y abril, lo que manifiesta un claro temor de las autoridades a que se pudiera malograr la cosecha, lo cual, como ya hemos comentado, llegó a ocurrir en 5 ocasiones.

Por otra parte, el exceso de lluvia en el invierno o en la primavera, también tiene consecuencias nefastas, si bien no suele, salvo algún caso excepcional como fue el año 1772, provocar la pérdida de la cosecha, aunque hace descender bastante los rendimientos, sobre todo cuando los temporales obligan a retrasar la sementera ${ }^{18}$. La anormal continuidad de las lluvias afecta especialmente a los trabajadores del campo, que se ven abocados a un paro estacional más prolongado de lo habitual, dejando incluso, por lo impracticable del terreno, de realizar las tareas de escarda, las únicas que podían ofrecer una remuneración significativa entre la siembra y la siega. La falta de trabajo y, por tanto, de ingresos en los llamados meses mayores, cuando las subsistencias estaban más caras, tenía sobre estos grupos desfavorecidos de la sociedad agraria una incidencia similar a una carestía de granos.

En general, la visión sobre la producción de cereales que nos ofrece el cuadro II respecto a la segunda mitad del siglo XVill no es muy positiva, predominando las cosechas por debajo de la media, hasta 30 , sobre las que superan ese nivel medio, las 20 restantes. Podemos introducir matices sobre la evolución del periodo comentando los datos de los sucesivos quinquenios. Así, comenzamos con los años 1750-54 en los que los malos resultados de 1750 y 1753 quedan compensados por las buenas o muy buenas cosechas de los otros tres años, por lo que el periodo podemos considerarlo equilibrado. Por su parte, el quinquenio de 1755 a 1759 marca una tendencia ligeramente positiva, debido a que no se contabiliza ningún año malo o catastrófico. Los cuatro quinquenios siguientes, que engloban los años 1760-1779 son todos negativos, predominando las cosechas deficitarias, 13 , de las cuales 5 fueron malas y 1 catastrófica, sobre las positivas, 7 , con sólo dos recolecciones buenas. Señalar que los malos resultados de este periodo se confirman en otros espacios de la geografía española, al menos, en el centro de la península y en el levante ${ }^{19}$. La incidencia que tuvo esta etapa de 20

17. Aspectos señalados por HERRERA Y DOBLAS, J.: Cereales y leguminosas, tubérculos y raices. Biblioteca agrícola San Marín, Madrid, s.f. (principios del siglo XX), p. 17.

18. Herrera y Doblas, J.: Op. Cit., p. 63, indica que una siembra en su tiempo es fundamental, ya que sembrando tardío «las heladas y lluvias del invierno afectan más a una semilla débil, y las calores primaverales hacen madurar a una planta que ha tenido un corto periodo de crecimiento».

19. Así, en la Mancha, de las 18 cosechas deficitarias que se citan entre 1750 y 1800 , hasta 9 se dan en el periodo 1760-1779, Días-Pintado, J.: Art. Cit., pp. 130-135. En Mallorca, según Vidal, J. J.: «Técnicas, rendimientos y productividad agrícola en la Mallorca moderna», La economia agraria en la historia de España. Propiedad, comercialización, rentas, Madrid, 1979, pp. 47-52, los peores años fueron los comprendidos entre 1760 y 1779 . También inciden en dichos años los estudios referidos al reino de Valencia, así PALOP, J. M.: Hambre y lucha antifeudal. Las crisis de subsistencia en Valencia (siglo XVIII), Madrid, 1977; y ALBEROLA, A.: «Abasto urbano y protesta popular en tierras valencianas durante el siglo XVIb», 
años no es tanto debida a la intensidad de la escasez como a su continua reiteración, que debió pesar sobre el ánimo y los propósitos de los labradores. La situación mejora, ostensiblemente, durante el quinquenio de 1780 a 1784 , ya que nos encontramos, por primera y única vez, con 4 buenas cosechas consecutivas, cadena que se rompe con la catastrófica cosecha del año 1784 , la cual no es sino un preludio del muy negativo quinquenio siguiente. En efecto, los años 1785-1789, salvo la normal recolección de 1788, presentan cosechas siempre deficitarias, siendo catastrófica la de 1787 . Al equilibrio del quinquenio 1790-1794, donde dos malas cosechas fueron compensadas por una buena y otra excelente, la de 1790 , le sigue un último quinquenio de nuevo claramente negativo, en el que la excelente recolección de 1798 no puede compensar las otras cuatro cosechas deficitarias. Por tanto, hay que reiterar esa perspectiva nada satisfactoria que tenemos de la segunda mitad del siglo XVIIl con respecto a la producción en la Baja Andalucía, aspecto que resulta de vital importancia si tenemos en cuenta que en ese mismo contexto temporal se está produciendo un moderado pero continuo incremento de la población, lo que genera una mayor demanda de alimentos.

Ello nos lleva a una última cuestión que no podemos dejar de plantear: la de la estrecha relación entre la producción agraria y la población. Como se demostró hace ya bastantes años, la perdida de la cosecha de cereal, elemento básico de la alimentación humana de la época, tenía unas graves repercusiones demográficas ${ }^{20}$. Las llamadas crisis agrarias, provocaban alteraciones en la normal dinámica de la población, sobre todo incrementando la mortalidad, ya sea por muertes directas ocasionadas por el hambre o por la mayor incidencia de las enfermedades en unos cuerpos desnutridos, pero también ralentizando el ritmo de nacimientos y matrimonios. El cuadro III nos sirve para poder captar la posible incidencia demográfica que las fluctuaciones de las cosechas, en especial cuando éstas eran deficitarias, tuvieron en Jerez de la Frontera.

\section{Cuadro III}

Cosechas y variables demográficas en Jerez de la Frontera

\begin{tabular}{|c|c|c|c|c|c|}
\hline A ̃̃OS & COSECHA & BAUTIZOS & DEFUNCIONES & BAUT. - DEFUN. & MATRIMONIOS \\
\hline 1750 & MM & 980 & 474 & 506 & 216 \\
\hline 1751 & N+ & 674 & 545 & 129 & 257 \\
\hline 1752 & MB & 920 & 490 & 430 & 260 \\
\hline 1753 & MM & 963 & 571 & 392 & 271 \\
\hline
\end{tabular}

en DE BERNARdo ARES, J. M. y GONZALEZ BeltrÁN, J. M. (Eds.): La administración municipal en la Edad Modernat, Cádiz, 1999, pp. 321-339.

20. Son ya clásicos los trabajos de GOUBERT, P.: Beauvais et le beauvaisis de 1600 à 1730. Contribution à I'histoire sociale de la France du xvile siècle, París, 1960 y Meuvret, Jean: «Les crisis de subsistance et la demographie de la France d'Ancien Régime», Etudes d'histoire économique, París, 1971, pp. 271 -278. En España, ANes, G.: Las crisis agrarias..., y PERÉz MOREDA, V.: Las crisis de mortalidad en la España interior (siglos $X V /-X I X$ ), Madrid, 1980. 


\begin{tabular}{|c|c|c|c|c|c|}
\hline AÑOS & COSECHA & BAUTIZOS & DEFUNCIONES & BAUT. - DEFUN. & MATRIMONIOS \\
\hline 1754 & MB & 933 & 592 & 341 & 250 \\
\hline 1755 & B & 969 & 529 & 440 & 354 \\
\hline 1756 & $\mathrm{~N}+$ & 1219 & 555 & 664 & 383 \\
\hline 1757 & $\mathrm{~B}$ & 1229 & 592 & 637 & 387 \\
\hline 1758 & $\mathrm{~N}+$ & 1127 & 663 & 464 & 294 \\
\hline 1759 & $B$ & 1187 & 725 & 462 & 303 \\
\hline 1760 & $\mathrm{~N}+$ & 1028 & 855 & 173 & 248 \\
\hline 1761 & $B$ & 1077 & 706 & 371 & 266 \\
\hline 1762 & $\mathrm{~N}-$ & 1165 & 523 & 642 & 310 \\
\hline 1763 & $\mathrm{MM}$ & 1037 & 561 & 476 & 232 \\
\hline 1764 & $\mathrm{Nt}$ & 968 & 568 & 400 & 261 \\
\hline 1765 & $\mathrm{M}$ & 1088 & 606 & 482 & 194 \\
\hline 1766 & B & 898 & 756 & 142 & 222 \\
\hline 1767 & $\mathrm{MM}$ & 1016 & 725 & 291 & 222 \\
\hline 1768 & $\mathrm{M}$ & 877 & 801 & 76 & 218 \\
\hline 1769 & $\mathrm{~N}+$ & 926 & 740 & 186 & 194 \\
\hline 1770 & $\mathrm{~N}-$ & 910 & 662 & 248 & 278 \\
\hline 1771 & $\mathrm{~N}-$ & 1003 & 554 & 449 & 358 \\
\hline 1772 & $M$ & 1025 & 512 & 513 & 314 \\
\hline 1773 & $\mathrm{M}$ & 1037 & 499 & 538 & 260 \\
\hline 1774 & $\mathrm{~N}-$ & 946 & 487 & 459 & 228 \\
\hline 1775 & $B$ & 1014 & 4998 & 516 & 292 \\
\hline 1776 & $\mathrm{~N}-$ & 973 & 596 & 377 & 324 \\
\hline 1777 & $\mathrm{~N}+$ & 1048 & 482 & 566 & 241 \\
\hline 1778 & $\mathrm{~N}-$ & 968 & 755 & 213 & 216 \\
\hline 1779 & $\mathrm{~N}+$ & 1014 & 506 & 508 & 221 \\
\hline 1780 & $\mathrm{~B}$ & 919 & 696 & 223 & 239 \\
\hline 1781 & B & 915 & 590 & 325 & 206 \\
\hline 1782 & $\mathrm{MB}$ & 942 & 652 & 290 & 337 \\
\hline 1783 & $\mathrm{~N}-$ & 1017 & 563 & 454 & 300 \\
\hline 1784 & $\mathrm{MM}$ & 1052 & 565 & 487 & 298 \\
\hline 1785 & $\mathrm{~N}-$ & 849 & 1031 & -182 & 186 \\
\hline 1786 & $\mathrm{~N}-$ & 844 & 1284 & -440 & 192 \\
\hline 1787 & $\mathrm{M}$ & 716 & 822 & -106 & 261 \\
\hline 1788 & $\mathrm{~N}+$ & 999 & 576 & 423 & 260 \\
\hline 1789 & $\mathrm{~N}-$ & 912 & 657 & 255 & 283 \\
\hline 1790 & $\mathrm{MB}$ & 1141 & 666 & 475 & 370 \\
\hline
\end{tabular}




\begin{tabular}{|c|c|r|r|r|c|}
\hline \multicolumn{1}{|c|}{ AÑOS } & COSECHA & BAUTIZOS & DEFUNCIONES & BAUT. - DEFUN. & MATRIMONIOS \\
\hline 1791 & N+ & 1165 & 530 & 635 & 334 \\
\hline 1792 & N- & 1099 & 591 & 508 & 337 \\
\hline 1793 & MM & 1037 & 601 & 436 & 283 \\
\hline 1794 & N+ & 916 & 558 & 358 & 299 \\
\hline 1795 & N- & 1151 & 557 & 594 & 305 \\
\hline 1796 & N- & 1116 & 596 & 520 & 245 \\
\hline 1797 & N- & 1035 & 709 & 326 & 247 \\
\hline 1798 & B & 942 & 842 & 100 & 255 \\
\hline 1799 & N- & 1125 & 650 & 475 & 304 \\
\hline PROMEDIO & & 1002,22 & 637,28 & 364,94 & 272,3 \\
\hline
\end{tabular}

La catastrófica cosecha de 1750 no provoca aumento alguno de la mortalidad, pero si que hace caer en un 20,7\% los matrimonios, lo que repercute en un descenso de hasta el $32,7 \%$ en los bautizos del año 1751. La también catastrófica recolección de 1753 no tiene efectos demográficos aparentes, quizás porque se contaba todavía con excedentes de la muy buena cosecha de 1752. Nuevamente, en 1763 tenemos una cosecha catastrófica, pero sólo incide en una caída del 14,8\% de la nupcialidad. Este año puede considerarse el inicio de uno de los ciclos más negativos del siglo, que se extiende hasta 1773. Destacan malas recolecciones en 1765, 1767 y 1768 . Esta reiteración de cosechas muy deficitarias provoca un aumento por encima del 15\% de las defunciones en el cuatrienio 1766-1769, destacando el año 1768 con un $25,7 \%$ de incremento de la mortalidad. Igualmente, los años 1766 y 1768 presentan descensos moderados en el número de bautizos, entre el 10 y el $12 \%$. Por último, la insatisfactoria situación origina una bajada de la nupcialidad en el quinquenio 1765-1769, en todos las anualidades superior al 18\%, descollando los años 1765 y 1769 con desviaciones sobre la media anual de matrimonios del $28,8 \%$ en ambos casos. El resultado de todas estas variables deja una profunda huella en la evolución demográfica de Jerez, ya que si durante el quinquenio de 1761-1765 el crecimiento vegetativo se cuantifica en números absolutos en 2.371 personas, el del quinquenio 1766-1770 se sitúa en unos escasos 943 individuos, en torno al 50\% del crecimiento medio normal del periodo. Dos nuevas malas cosechas se dan en los años 1772 y 1773 , en este caso con mínimos efectos, tan sólo un leve descenso de los matrimonios en 1774.

En 1783 se inicia un nuevo ciclo de cosechas deficitarias que se mantiene hasta 1789 , destacando una recolección catastrófica en 1784 y otra mala en 1787. La incidencia sobre la población de Jerez es muy dramática, con tres años, 1785-1787, en los que el crecimiento vegetativo llega a ser negativo, pero hay que tener en cuenta que durante el trienio de 1784-1786 asola la localidad una epidemia de fiebres tercianas, por lo que las malas cosechas no son exclusivamente las causantes de la ruptura del normal ritmo demográfico.

En la década de 1790 tenemos una recolección muy mala en el año 1793, aunque no deja huella alguna en las series demográficas. En el trienio 1795-1797 se sucedie- 
ron tres cosechas que sin ser malas fueron escasas, lo que unido a su reiteración y al bloqueo, en 1797, de la bahía de Cádiz por la armada inglesa, lo que imposibilita la entrada de trigo ultramarino, va a provocar una crisis demográfica durante los años 1797-1798, de forma especial este último año, con un incremento de la mortalidad del $32,1 \%$ por encima de la media.

La incidencia de las cosechas exiguas e insuficientes sobre la dinámica demográfica no sólo es patente sino que, además, se muestra compleja, con efectos más allá de las muertes por falta de subsistencias. El descenso, por ejemplo, en el número de matrimonios, coincidiendo con las recolecciones deficitarias, nos viene a indicar como en una sociedad eminentemente agraria como la del Antiguo Régimen, que tiene en la actividad agrícola no sólo su fuente de alimentos, sino también el fundamento de sus ingresos y-o de su ocupación laboral, los resultados de la producción, cuando éstos no alcanzan los mínimos previstos u ordinarios, provocan desajustes en la planificación del ciclo vital y el desvanecimiento de las expectativas de un futuro afortunado que las personas hubieran podido esbozar o imaginar.

Ante la significación de los fenómenos atmosféricos y su persistente incidencia sobre el sector agrario, otras adversidades naturales, dada su aparición más esporádica, quedan en un segundo plano, aunque no por ello sus consecuencias dejan de ser sobradamente relevantes. Entre estos eventos extraordinarios y, a la vez, catastróficos, que puntualmente inciden sobre la actividad agraria, destaca el de las plagas. Dependiendo de su intensidad pueden ocasionar desde una merma en la producción a la pérdida de los cultivos afectados.

En la Edad Moderna la plaga que más se repetirá será la del insecto ortóptero denominado langosta, a cuyo poder destructivo, los grandes enjambres devoran toda planta comestible que encuentren a su paso, se une la intimidación y el desasosiego que ocasionan en una población muy influenciada por la religión, que relaciona la manifestación de esta plaga con la justicia divina, que castiga con ella los pecados de los hombres, de la misma forma que en la antigüedad bíblica mortificó al pueblo egipcio. Estas ideas impidieron que tanto las características biológicas como el comportamiento de la langosta fueran estudiadas y conocidas científicamente hasta finales del siglo XVIII" coincidiendo con una mayor preocupación y atención sobre este problema agrario por parte de las autoridades estatales ${ }^{22}$.

La langosta estaba tradicionalmente asentada en las tierras yermas y de pastos de la España meridional, convirtiéndose en una plaga cuando se originaba una reproduc-

21. Señalamos los trabajos de BowLES, Guillermo: Introducción a la Historia Natural y a la Geogrufia fisica de España, Madrid, 1782 (la primera edición es de 1775) e Historia Natural de la langosta de España y modo de destruirla, Madrid, 1825. También SALIDO Y EsTraDA, Agustín: La langosta. Compendio de todo cuanto más notable se ha escrito sobre la plaga, naturaleza, vida e instintos de este insecto, Madrid, 1874.

22. El año 1755 el Consejo de Castilla redactó una Instrncción fornada sobre la experiencia práctica de varios años para conocer y extinguir la langosta en sus tres estados de ovación, feto o mosquito y adulia; con el modo de repartir y prorratear los gastos que se hicieren en este trabajo, que fue remitida a todas las localidades. 
ción excesiva de la especie. Este hecho se había convertido en una constante histórica ${ }^{23}$, y la segunda mitad del siglo XVIII no constituyó ninguna excepción, más bien se apunta a un recrudecimiento de la plaga, tanto por el mayor número de veces que se exterioriza como por los considerables daños que ocasiona ${ }^{24}$.

En Jerez de la Frontera, como ya apuntamos, se dieron, entre 1750 y 1799 , hasta seis años con plaga de langosta, en concreto $1755,1757,1781,1782,1795$ y $1796^{25}$. De ellas podemos comentar algunos aspectos. Primero, que suelen coincidir con periodos cronológicos en los que predomina la sequedad y el calor, aspectos que influyen de dos formas. Por un lado los insectos, que el frío parece aletargar, se muestran más activos, se desplazan a más distancia y de manera más rápida. Por otro, la sequía disminuye o deja sin vegetación los lugares naturales donde se ubica la langosta, obligándola a buscar su sustento en otros parajes ${ }^{26}$. En este sentido, todos los años reseñados fueron muy secos; así, por ejemplo, la recogida de langosta en Jerez a principios de mayo de 1755 estaba resultando muy dura para los trabajadores, ya que se procedía a la misma «en lo riguroso del tiempo motivado de las muchas calores»"

Un segundo aspecto se detecta en la documentación, y es que el insecto era perenne en determinadas zonas de pastos del término jerezano, en las cuales era donde reiteradamente se manifestaba en forma de plaga. Cuando en 1783 se dispuso por el Intendente inspeccionar los campos pues había alarma de plaga, las autoridades de Jerez acordaron acatar la orden, pero «en la seguridad de que en el día de hoy no hay aún sospecha de que permanezcan en los sitios que otras veces ha habido» ${ }^{28}$.

Por último, especificar que ninguna de las plagas de langosta mencionadas provocó en Jerez daños importantes en los cultivos, como lo demuestra lo favorable de las cosechas de esos años, con la salvedad de 1795 y 1796 , cuando las recolecciones fueron normales pero con tendencia a la baja ${ }^{29}$. Si sufrieron, en cambio, las finanzas

23. Datos sobre esta plaga en el siglo XV1 son aportados por VASSBERG, D. E.: Tierra y sociedad en Castilla, Barcelona, 1986, p. 255.

24. DiAZ-PINTADO, J.: Art. Cit., pp. 145-146, recoge en la documentación de los concejos de La Mancha más alusiones a la langosta en la segunda mitad del siglo XVIII, con 16 años de plaga, que en la primera mitad. Sobre los graves efectos que provocaron tenemos el ejemplo de lo ocurrido en el reino de Valencia. comentado por AL.BEROLA, Armando: «Procesiones, rogativas, conjuros y exorcismos: el campo valenciano ante la plaga de langosta de 1756\%, Revista de Historia Moderna. Anales ae la Universidad de Alicante, 21 (2003), pp. 383-410.

25. Las del periodo 1755-1757 parecen ser las más importantes, comenzó en Extremadura, para seguir por La Mancha, Andalucia, Murcia y Valencia. Las de 1781-1782 se dejaron sentir con fuerza en La Mancha. Diaz-Pintado, J.: Art. Cit., p. 146 y Alberol.A, Armando: «Procesiones, rogativas...», pp. 390-397.

26. Díz-PiNTADo, J.: Art. Cit., p. 149, señala esta condición climática, aunque reconoce que se dan algunas plagas en años más frescos. VASSBERG, D. E.: Op. Cit., p. 255, también indica la coincidencia entre sequía y plaga de langosta, sucediéndose en este orden.

27. A.M.J.F., A.C., cabildo 9-5-1755, f. 498.

28. A.M.J.F., A.C., cabildo 6-11-1783, f. 178. Entre estos lugares destacan los llanos de Caulina y el Hato la Carne.

29. La incidencia de las plagas de langosta era muy azarosa, ya que dependia de los vientos que facilitaban el movimiento de los insectos. En 1781 la plaga no afectó a los cultivos de Jerez ni a los de El Puerto, pero sí, y mucho, a los de Rota, otra localidad colindante. IGLEsIAS, J. J.: Op. Cit., p. 126 
del municipio que tenían que sufragar los gastos de recogida del insecto. Así, en 1757 el desembolso ascendió a la cantidad de 32.558 reales y, en 1781, hasta los 36.329 reales $^{30}$. El determinar si estas cifras son elevadas o no conlleva conocer los ingresos de la localidad concreta, que en el caso de Jerez rondaban los 300.000 reales, por lo que estamos hablando de un $12 \%$ del presupuesto, cantidad no excesiva pero de difícil asimilación por una hacienda local fuertemente endeudada. Casi siempre se optaba por el repartimiento a la población, lo cual, además de ocasionar nuevos gastos por la cobranza, no aseguraba, por impagos, la percepción total de la imposición.

Esta misma incidencia negativa sobre las finanzas públicas de Jerez es la consecuencia más sobresaliente de la plaga de oruga que sufrieron las arboledas de bellota administradas por el concejo local en los años 1773-177431. En septiembre de 1773 los peritos apreciadores que reconocían las dehesas de bellota advertían que muy pocos cerdos podrían ser admitidos a la montanera otoñal, debido a que «el fruto de bellota está enteramente perdido a causa de la multitud de oruga que tienen los árboles al tiempo de retoñarse, las cuales se comen no sólo el fruto sino también las mismas hojas». En efecto, la cabida de las dehesas bajó, de una media los años anteriores de entre 3.000 y 4.000 cerdos, a tan sólo 1.098 puercos, por lo que los ingresos que generaba el canón impuesto para poder beneficiarse de las bellotas públicas cayó en picado, tanto que el déficit del bienio 1773-1774 alcanzó la cifra de 153.089 reales $^{32}$.

$\mathrm{E}$, igualmente, otra adversidad natural, los incendios, también se relaciona con los montes públicos y su explotación por el concejo municipal. Como hemos visto, existían múltiples dehesas con alcornoques y encinas que eran aprovechadas por el ganado porcino, lo cual no era posible si algún fuego quemaba los árboles. Ello redundaba en un descenso de ingresos para las arcas concejiles. Los incendios eran habituales, pero destaca el del año 1782, que quemó una circunferencia de dos leguas, perdiéndose, aunque el dato está claramente exagerado, «millones de árboles»" ${ }^{33}$. Muchos de estos fuegos no tienen un origen fortuito, sino que están relacionados con las roturaciones de tierras y con la actividad de carboneros ilegales.

Para finalizar con las distintas adversidades naturales que se dieron en la localidad de Jerez de la Frontera en la segunda mitad del siglo XVIII, haremos referencia a las epidemias que afectaron a su población. Estas fueron de fiebres tercianas o paludismo ${ }^{34}$. Su

30. Los datos en A.M.J.F., A.C., cabildo 22-7-1757, f. 89 y legajo 171, exp. 5.308.

31. La plaga fue detectada en abril de 1773. A.M.J.F., A.C., cabildo 24-4-1773, f. 713. Las consecuencias de estas plagas menores apenas son tenidas en cuenta. ALBEROLA, A.: «Abasto urbano y protesta...», p. 335 , hace referencia a como una plaga de pulgón, en 1766 , contribuyó a degradar la ya mala situación económica de Elche.

32. Esta información en GONZÁLEZ BELTRÁN, J. M.: Reformismo y administración local en la provincia de Cádiz durante el reinado de Carlos III, Jerez de la Frontera, 1991, p. 479.

33. Sobre el fuego de 1782, A.H.M.J., Leg. 4, exp. 133.

34. Sobre esta enfermedad en el siglo XVIII pueden consultarse los trabajos de PESET, Mariano y José Luis: «Cultivos de arroz y paludismo en la Valencia del siglo XVIII», Hispania, 121 (1972), pp. 277-375; ALberola, A.: «Una enfermedad de carácter endémico en el Alicante del siglo XVIII: las fiebres tercianas», Revista de Historia Moderna. Anales de la Universidad de Alicante, 5 (1985), pp. 127-140 y 
aparición y propagación precisaba y se veía favorecida por algunos condiciones. Así, la presencia de aguas estancadas permitía la reproducción del mosquito transmisor. Por otro lado, el que la población o gran parte de ella se encontrara con escasas defensas por una deficiente alimentación propiciaba más facilidad de contagio y, a la vez, una más alta mortalidad. Por ello, serán los años con inviernos y primaveras muy lluviosos, que dejan muchas charcas y pozas infectas, y que, por otra parte, suelen impedir a los empleados del campo realizar sus trabajos y, por lo tanto obtener ingresos con los que sufragar sus necesidades alimenticias, en los que se dan las condiciones más propicias para que la epidemia surja.

En Jerez nos constan al menos dos periodos epidémicos de fiebres tercianas. E1 primero en torno al año $1760^{35}$, que causó un incremento del $34,1 \%$ sobre la media de las defunciones, no siendo más dañina debido a que las tres cosechas de 1759-1761 fueron todas buenas. No ocurrió lo mismo en el otro periodo de epidemia, el que se da entre los años 1784-178736, en el que los efectos nocivos de las fiebres se ven reforzados por una climatología invernal muy adversa y por la carencia de alimentos, con varias cosechas deficitarias, en especial la catastrófica de 1784. La conjunción de la epidemia y de la crisis de subsistencia fue letal para la población jerezana, en especial para el grupo sociolaboral de los trabajadores del campo. En junio de 1786 las autoridades locales recibieron un informe solicitado a los médicos sobre las consecuencias de la epidemia. En él, los facultativos indicaban que Jerez tenía en torno a 44.000 habitantes, la mayoría jornaleros que se ocupaban en la actividad agrícola, la principal y casi única de la localidad, para, a continuación, lanzar un fuerte alegato contra la estructura socioeconómica jerezana. Se preguntaban...

«¿Qué se hará de tan gran porción de pueblo si se descuidan las artes y se pone solo la atención en la agricultura y cría de ganados?. Perecer en la miseria, respondemos nosotros como ha sucedido en Jerez en la presente epidemia. Que espectáculo tan desagradable ver un padre de familia lánguido, extenuado de una dilatada y rebelde enfermedad, que sufre una gran inapetencia cuando aún no tiene lo preciso para poder vivir, que ve a sus tiernos $\mathrm{y}$ amados hijos en los brazos de la muerte, a quien precipitan unas malas y pestilentes

«Tercianas y calenturas en tierras meridionales valencianas: una aproximación a la realidad médica y social del siglo XVIID), Revista de Historia Moderna. Anales de la Universidad de Alicanie, 17 (1998-99), pp. 95-112; PÉREZ MOREDA, V:: «Crisis demográfica y crisis agrarias: paludismo y agricultura en España a fines del siglo XVIIl», en Congreso de Historia Rural. Siglos XV al XIX, Madrid, 1984, pp. 333-354.

35. Noticias de esta epidemia en A.M.J.F., A.C., cabildo 2-6-1760, f. 107. También se constata, en dicho año, en Alicante. AlbEROLA, A.: «Tercianas y calenturas...», p. 101.

36. La epidemia de paludismo de estos años fue prácticamente general en todo el levante y sur de la península. Según AlberolA, A.: «Tercianas y calenturas...», p. 102, comenzó a principios de 1783 en Lérida, expandiéndose a toda Cataluña y, a continuación, a Aragón, Valencia, Castilla la Nueva, La Mancha, Extremadura y Andalucía. PEREz MOREDA, V: Las crisis de mortalidad..., pp. 336-360, analiza la encuesta of icial realizada a principios de 1787 sobre la incidencia de la enfermedad en 1786 y recoge que el número de enfermos ascendió a 875.945 , de los cuales 77.661 fallecieron. Recalca que el escrutinio no fue completo, por lo que las personas fallecidas llegarian a las 100.000 . 
viruelas, que su consorte anhela y se fatiga para traerles el sustento después de haber vendido cuanto tenía y pudo y que aún no recoge lo preciso. Una madre de familia a quien la epidemia acaba de quitarle el marido que se ve en la cama impedida y que sus hijuelos se le separan a buscar quien los socorra (...). Podremos referir con serenidad la suerte de aquellos otros que devorados por el hambre cuando buscaban quien los socorriese hallaron la muerte en la mayor concurrencia en medio de las calles. ARGUMENTOS PARA PROBAR QUE LA NECESIDAD HA PRODUCIDO LAS FUNESTAS CONSECUENCIAS QUE NO CAUSARÍA POR SÍ MISMA LA EPIDEMIA. En efecto, no las causó en los pudientes, de quienes no murió ni uno, aún a pesar de su tenacidad. ¿Se mudaría la naturaleza de éstos con su estado? (...). Que la agricultura sin artes es lánguida porque la mujer, las hijas y los niños de un labrador, donde no se ocupan en las fábricas, son una carga, aunque indispensable, que abruma al jornalero y enflaquece al labrador más acomodado. En Jerez hay otra razón y es que la agricultura dividida en grandes cortijos no puede redituar a proporción a su tamaño, es muy corto el número de pequeños labradores y en las grandes haciendas no se cultiva como en las pequeñas heredades».

Los médicos de Jerez, al margen de otras consideraciones superiores, planteaban, como por las mismas fechas lo hacían el Real Proto-Medicato y la Junta de Sanidad estatal $^{37}$, las desigualdades sociales ante la enfermedad, y cómo la gente con escasos recursos, en este caso los jornaleros del campo, eran los más afectados, debido a su debilidad y condiciones de vida, por los envites epidémicos. El cabildo municipal, acordó remitir dicho informe al Intendente, pero, con un cinismo que delata su parte de responsabilidad, indicaba que lo hacía «sin embargo de no conformarse en cuanto a las concausas de policía que han señalado los expresados facultativos ${ }^{38}$.

En general, el brote epidémico de 1785-1787, como se observa en el cuadro III, provoca unas 1.250 defunciones por encima de las cifras normales, lo que equivale a un aumento medio de la mortalidad del $67 \%$, aunque hay que recalcar como en el año 1786 se 1 legó a alcanzar el 101,5\%, todo ello con su corolario de descenso en el número de matrimonios y de bautizos. Por otra parte, la realización de las faenas agrícolas se vio también afectada, llegando a reconocer el concejo municipal, en 1786, que la situación, por los muchos jornaleros enfermos, era muy delicada, ya que por haberse repetido «la calamidad con tanto exceso no faltan algunos cortijos y caserios de campo que quedan absolutamente cerrados $\rangle^{39}$.

Este es el panorama de las adversidades naturales que incidieron sobre el sector agrícola de Jerez de la Frontera en la segunda mitad del siglo XVIII, en el próximo apartado veremos como respondieron frente a ellas las autoridades de la localidad.

37. Los dictámenes de estas instituciones y las semejantes opiniones de algunos pensadores son recogidas por Pérez Moreda, V: Las crisis de mortalidad...», pp. 224-231 y 336-360. Esta selección social de la epidemia de 1784-I787 también recalcada por ALBEROLA, A.: «Tercianas y calenturas...», p. I05, para el caso de Elche; y por IGlesias, J. J.: Op. Cit., p. 118, para EI Puerto de Santa María.

38. A.M.J.F., A.C, cabildo 12-6-1786, f. 177.

39. A.M.J.F., A.C., cabildo 24-7-1786, f. 213. 


\section{LA ACTUACIÓN POLÍTICA}

Durante todo el Antiguo Régimen, coincidiendo con una etapa de casi nula descentralización administrativa de los organismos de poder estatales, son los concejos de cada municipio los que tienen, más que las competencias, la obligación de atender las necesidades de sus vecinos. Funciones primordiales como podían ser el abastecimiento urbano, la regulación de las actividades económicas o la disposición de los aspectos sanitarios y de beneficencia, recaen de forma exclusiva sobre los oficiales y cargos concejiles, ejerciendo las instancias superiores del Estado (Intendentes, Secretarios, Consejos...), tan sólo una fiscalización diferida. De esta forma, cuando alguna de las adversidades naturales que venimos comentando incidía sobre una localidad son los cargos públicos de la misma los que tienen que movilizarse para mitigar sus efectos, plantear soluciones y solicitar, si fuera preciso, ayuda estatal. Las actuaciones llevadas a cabo por las autoridades concejiles frente a las calamidades naturales se pueden clasificar en tres grupos: las de carácter religioso; las de contenido económico; y las terceras serían una mezcla entre acciones de orden público y medidas benéficas. Aunque las tres suelen estar coordinadas, ya que se trata de las distintas partes de una respuesta conjunta a un problema concreto, para facilitar su análisis vamos a ver cada grupo por separado.

\section{III.1. Buscando la intercesión divina}

En una sociedad en la que la religión lo impregna todo, el advenimiento de adversidades naturales se relaciona, e incluso se explica, con argumentos religiosos. El azote de las calamidades es percibido por los creyentes, y en ello inciden los eclesiásticos, como pruebas o penitencias que Dios aplica con el objetivo de advertir o castigar a los fieles por seguir conductas que se separan o son contrarias a los preceptos cristianos. Por esta cuestión, la manifestación de cualquier desgracia de orden natural en el «valle de lágrimas» terrenal requiere, amén de otros tipos de respuesta, exhibiciones de carácter religioso, mediante las cuales se reconozcan los pecados, se haga penitencia y se suplique por el cese del infortunio ${ }^{40}$.

Entre las diversas ceremonias establecidas para tales efectos destacan, además de las procesiones, las rogativas. El origen de éstas se remonta al siglo $\mathrm{V}$ y desde entonces su uso se fue haciendo más general, favorecido por una institución eclesiástica que recalca con estas funciones su papel de intermediaria de la gracia divina y, al mismo tiempo, el sentimiento de culpa de los creyentes ${ }^{41}$. Pero si la Iglesia las oficia es, generalmente, a instancia de las autoridades civiles, de los cabildos municipales,

40. Observaciones sobre estos aspectos religiosos relacionados con las adversidades en CALvo PovaTO, J.: «Religiosidad y calamidades en tierras de Córdoba a finales del siglo Xvil», Hispania Sacra, XXX1x, 79 (enero/junio 1987), pp. 185-200 y CORTÉS PEÑA, A. L.: «Entre la religiosidad popular y la institucional. Las rogativas en la España Moderna», Hispania, LV/3, 191 (1995), pp. 1027-1042.

41. Algunos apuntes sobre estos orígenes, con notas bibliográficas, en ALBEROLA, A.: «Procesiones, rogativas...», p. 399. 
los cuales proceden de motu propio, tras evaluar la situación calamitosa, o atendiendo la petición de determinados colectivos socioeconómicos afectados. Tanto es así, que en el año 1770 se promulgó una orden por la cual las rogativas deberían hacerse mediante acuerdos de los cabildos municipal y eclesiástico, pero siempre correspondiendo la iniciativa a la autoridad secular ${ }^{42}$, normativa que, manteniendo los clásicos vínculos Iglesia-Estado, viene a incidir en la trayectoria de los gobiernos ilustrados de afirmar la supremacía del poder civil, a la vez que regula y politiza, estableciendo trámites burocráticos, un evento religioso. Comentar que en Jerez, a partir de la fecha de esta ley, 1770, y hasta 1799, límite temporal del estudio, son algo más abundantes las alusiones a rogativas que se recogen en las actas capitulares, ya que si bien las adversidades se multiplican por tres con respecto al periodo 1750-1770, las menciones a actos litúrgicos se cuadruplican, lo que viene a confirmar la institucionalización secular que estos asuntos empiezan a adquirir.

Las rogativas y otros actos piadosos fueron moneda corriente en la sociedad del siglo XVIII, procediéndose a su celebración, como ya se ha dicho, cuando las calamidades y desgracias naturales hacían acto de presencia, en especial, la meteorología adversa ${ }^{43}$. Es por esta relación entre rogativa y climatología por la que los paleoclimatólogos han sido los que más a fondo han estudiado estos actos litúrgicos y planteado una metodología para su uso, de tal forma que según fuera el tipo de rogativa realizada se podía establecer la menor o mayor intensidad del fenómeno meteorológico ${ }^{44}$. Aunque aceptando las premisas básicas expuestas por estos investigadores del clima, el historiador debe proceder a un análisis más extenso y profundo, ya que el modelo de rogativa o acto religioso que se oficie no depende exclusivamente del factor climático, sino que hay que introducir otros elementos como los económicos o de orden público. En efecto, en ocasiones las rogativas o no se realizaban o se hacían de forma secreta, ya que como comentaban los ediles jerezanos en 1772, «hacer demostraciones de petición a Dios en otros términos -se entiende públicas- seria tal vez alterar al pueblo y que los comestibles tuviesen más alto precio del que hoy tienen $\rangle^{45}$. En estos casos, se temía que la celebración de rogativas confirmara a la población y a los especuladores la existencia de una situación difícil que estaba escapando al control de las autoridades. Al contrario, en ocasiones el acuerdo de efectuar rogativas tenía por finalidad, más que aplacar la justicia divina, el de calmar los ánimos de una plebe inculta y supersticiosa

42. Orden de 21-8-1770, Novisima Recopilación de las Leyes de España, Madrid, 1804, libro I, título I, ley 20. En A.M.J.F., A.C., cabildo 16-3-1772, ff. 98-101, se hacen referencias al contenido de esta norma.

43. Varios ejemplos en Díaz-PinTAdo, J.: Art. Cit., pp. 124 y 143 y en Alberola, A.: «La percepción de la catástrofe...», pp. 259-263.

44. El precursor de estos estudios fue el historiador GIRALT, E.: «En torno al precio del trigo en Barcelona durante el siglo XVI», Hispania, XVIII (1958), pp. 38-61. Los aspectos metodológicos en BARRIENDOS, M.: Art. Cit., pp. 73-87 y ZAMORA PASTOR, R.: Op. Cit., pp. 49-70. Establecen la siguiente jerarquía de funciones: rogativa simple; rogativa con exposición del intercesor; procesión del intercesor; y acto extraordinario (peregrinación, inmersión del intercesor en un río o pozo, etc.).

45. A.M.J.F., A.C., cabildo 23-3-1772, f. 115. 
que exigía remedios, aunque fueran espirituales, para las desdichas que la aquejaban. Así, en 1793, el cabildo municipal de Jerez acordó hacer rogativas a la Virgen de la Consolación y a San Dionisio, considerando la continuidad de la sequía, pero sobre todo "escuchando los clamores de la gente del campo, cuyo trabajo va cesando enteramente con este motivo y las demás consecuencias que a esto se sigue ${ }^{46}$. En esta ocasión, la acción de bálsamo sobre las masas, al objeto de evitar disturbios, prevalece sobre cualquier peligro especulativo. En general, por lo que hemos podido observar en Jerez, el tipo de ceremonia religiosa no responde tanto al rigor de la calamidad como a las condiciones económicas, sociales, laborales y de seguridad que, como resultado de la adversidad pero también de otros factores, imperaran en el municipio, teniendo, igualmente en cuenta, que el análisis de la situación y la decisión final corresponde a los componentes del gobierno local, cuyos intereses concretos no tienen porque coincidir necesariamente con los generales del vecindario.

Para terminar, daremos algunos datos sobre estas ceremonias en la localidad de Jerez. Entre 1750 y 1799 nos encontramos con 14 adversidades que dieron lugar a la celebración de rogativas de diverso tipo. Si el total de las calamidades naturales constatadas en el periodo fue de 36 , resulta que un $38,9 \%$ de ellas obligó a realizar oficios religiosos. Las rogativas son utilizadas sobre todo ante adversidades climatológicas, nueve casos, un $64,3 \%$, destacando la sequía, ocho ocasiones, sobre la abundancia de lluvia, una incidencia. Pero hay otras desgracias que también obligan a recurrir a ceremonias religiosas. Así, las plagas, como las de langosta de 1755 y 1757, practicándose durante esta última una procesión con una reliquia especial, la cabeza de San Gregorio Ostiense, con cuya agua bendita, desde la torre de la colegial, se «bendijeron los campos por los cuatro vientos $»^{47}$, o la de oruga de 1773, ante la cual proponía el síndico procurador que «no discurriéndose en lo natural remedio para atajar este daño será preciso acudir a los que la iglesia tiene dispuestos para la exterminación de estos insectos, que son los conjuros y otros requisitos que se deben practicar por sacerdotes de la más ajustada vida y correspondiente opinión», siendo finalmente bendecidos los montes, por los frailes del convento de San José del Valle, con agua bendita de San Gregorio Ostiense $^{48}$. Por último, las epidemias de fiebres tercianas motivan la realización de rogativas los años 1785 y 1786.

La tipología de los actos religiosos es muy variada. Hay cuatro casos de rogativas simples, de las cuales dos son secretas. En tres ocasiones la rogativa recurre a un intercesor. Una sola vez se produce una procesión con dos imágenes. En tres casos las rogativas son el paso previo a una procesión. Finalmente, tenemos el año 1793, cuando lo pertinaz de la sequía desencadenó una sucesión de funciones religiosas: primero unas rogativas simples, luego la procesión de la Virgen de la Merced, más tarde rogativas a

46. A.M.J.F., A.C., cabildo 25-2-1793, f. 29

47. A.M.J.F., A.C., cabildo 22-7-1757, ff. 89 y 202. Sobre la peregrinación de esta reliquia desde su santuario en Navarra nos ofrece información ALBEROLA, A.: «Procesiones, rogativas, conjuros...», pp. 403-410. 48. A.M.J.F, A.C., cabildos 24-4-1773 y 5-5-1773, ff. 713-715. 
la Virgen de la Consolación y a San Dionisio y, por último, la procesión de la Virgen de las Angustias ${ }^{49}$. A todos estos actos se añaden las dos bendiciones de los campos ya reseñadas y cuatro funciones de acción de gracias.

En cuanto a los intercesores a los que se recurre destaca sobre todos la Virgen de la Merced, patrona de la localidad, que está presente en 11 actos, el 57,9\% de los organizados. La Virgen de la Consolación, que en el año 1600 ante una epidemia de peste fue la intercesora y benefactora de la ciudad ${ }^{50}$, también cuenta con gran fervor, por lo que se apela a ella en cuatro ocasiones. Luego tenemos a San Gregorio Ostiense, con dos actos, y a San Dionisio, patrono de Jerez, y la Virgen de las Angustias con una función cada uno.

\section{II.2. Las medidas económicas}

«El primer cuidado del gobierno de un pueblo es el que éste esté abastecido de todos los mantenimientos necesarios para la manutención de la vida», así lo manifestaba en su tratado de política municipal Santayana Bustillo, recogiendo no sólo la opinión generalizada sino el uso consuetudinariamente admitido ${ }^{51}$. Las autoridades concejiles fiscalizaron en todo momento el abastecimiento de los productos de primera necesidad, en especial del trigo ${ }^{52}$, actitud que proviene no tanto de la escasez de los víveres como de la inseguridad constante en la que se vivía de que éstos pudieran faltar, sensación que tiene su razón de ser, principalmente, aunque hay otros factores, en la desconcertante aparición y efectos de las adversidades naturales. Por otra parte, no hay que olvidar que son las crisis de subsistencia el mejor caldo de cultivo para el desarrollo de motines y revueltas, acontecimientos que no sólo ponen en peligro la paz social sino también el orden establecido, al cuestionar la capacidad de los gobernantes locales para desempeñar sus cometidos básicos. En esta línea, recordemos como tras los motines de 1766 el gobierno central procedió a una reforma de la institución concejil, al instaurar unos nuevos cargos municipales, los diputados del común, significativamente llamados «de abastos», cuya finalidad primigenia era la de intervenir en todo lo relacionado con el abastecimiento de la población ${ }^{53}$.

Veamos a continuación como actuaron las autoridades de Jerez de la Frontera en estas cuestiones. Cuando algún riesgo natural, preferentemente un fenómeno meteorológico inopinado, se hacía patente y ponía en peligro las cosechas el gobierno municipal debía actuar de manera diligente. Lo primero que se observa es una multiplicación

49. A.M.J.F., A.C., cabildos 2-1-1793, f. 13; 23-1-1793, f. 29; 25-2-1793, f. 42; y 6-3-1793, f. 56

50. Hecho comentado por SANCHO, Hipólito: Fiestas perpetuas votadas por la ciudad de Jerez de la Frontera desde el año 1600 a 1812, Jerez de la Frontera, 1959, p. 18.

51. Santayana Bustillo, Lorenzo de: Gobierno politico de los pueblos de España, Zaragoza, 1742. Reimpresa por 1.E.A.L., Madrid, 1978, p. 47.

52. Sobre el intervencionismo que afecta al trigo y al pan en Cataluña tenemos el trabajo de PÉREZ SAMPER, M. A.: «EI pan en la Barcelona moderna: poder municipal y abastecimiento», en DE BERNARDO ARES, J. M. y GONZÁlez BELTRÁn, J. M. (Eds.): Op. Cit., pp. 407-420.

53. La creación y funciones de estos cargos, para el caso de las localidades gaditanas, puede verse en GONZÁLEZ Beltrán, J. M.: Reformismo y administración..., pp. 86-93 y 191-217. 
en el número de reuniones del cabildo, pasándose en casos de gravedad a la formación de juntas o comisiones especiales que, con plenos poderes, pudieran proceder en todo momento, sin sujetarse a los formulismos rutinarios de las sesiones, poniendo en ejecución las medidas más convenientes ${ }^{54}$. Igualmente, los comisionados propuestos serían los encargados de visitar otras localidades al objeto de aprovisionarse de los granos que faltaban en Jerez. Y es que, ante el peligro de escasez o de carestía del trigo, una de las medidas más utilizadas era la de proceder a su acopio.

Siempre que se detectó la carencia de granos iniciaron las autoridades jerezanas las gestiones oportunas para adquirirlo en otros lugares. Así, quedan constatadas estas compras los años 1750, 1778, 1785 y 1793, todos ellos de cosechas deficitarias, destacando el primero y el último que las tuvieron catastróficas ${ }^{55}$. Generalmente se recurre al Ilamado trigo ultramarino, aquél que llegaba vía marítima, con preferencia desde otras zonas del Mediterráneo, a la bahía de Cádiz. El concejo de Jerez conocía, por pura experiencia, los beneficios de este punto de aprovisionamiento. Así, en 1753, contestando a una encuesta del Intendente de Sevilla, a la pregunta de ¿dónde -Cádiz, Sevilla o Málaga- le es más a propósito para abastecerse de trigo ultramarino?, afirma que «lo transporta con gran facilidad desde la bahía de Cádiz, por cuyo motivo está instruido y ya sabe como puede $y$ debe manejarse por sí en este punto" ${ }^{56}$. Los elementos positivos eran: la abundante oferta, ya que muchos comerciantes, conocedores de las carencias de trigo de un mercado de más de 200.000 personas en torno a la bahía, arribaban con sus cargamentos sin ser siquiera solicitados; la posibilidad de un transporte fácil y barato, desde la bahía a través del río Guadalete, hasta las inmediaciones de Jerez; y, por último, el hecho de que este trigo ultramarino tuviera un precio sensiblemente inferior al que rigiera en la zona, siempre entre un 5 y un $15 \%$ más barato ${ }^{57}$. Sobre esta cuestión del menor coste, hay que indicar que en ella incide el hecho de que, en los momentos de escasez o carestía, las autoridades estatales, de motu propio o a petición de los gobiernos locales u otras instituciones, solían rebajar las cargas fiscales que gravaban los géneros de abastos e, incluso, decretar una exención total mientras que durara la negativa situación ${ }^{58}$.

54. Referencias a estas juntas en A.M.J.F., A.C., cabildos 14-5-1750, f. 530; 24-4-1773, f. 710: 13-5-1785, f. $171 ;$ y 10-12-1793, f. 246. Las cuatro en años de malas cosechas.

55. Alusiones a estas adquisiciones de trigo en A.M.J.F., A.C., cabildos 29-7-1750, f. 562; 20-2-1778, f. 85; 2-4-1785, f. 126; y 24-12-1793, f. 255. Noticia, pero sin datos concretos, sobre la entrada de trigo los años 1763,1768 y 1780 , en A.M.J.F., Leg. 196, exps., $5.878,5.881$ y 5.887.

56. La encuesta en A.M.J.F., A.C., cabildo 6-6-1753, ff. 123-127.

57. Las grandes posibilidades que para el abastecimiento de trigo abria el tener un puerto marítimo cercano señaladas para los casos de Barcelona y Valencia por Pérez SAMPEr, M. A.: Art. Cit., p. 415 y PALOP, J. M.: Op. Cit., p. 29.

58. Nos consta como las autoridades de Jerez solicitaron la libertad de impuestos para el trigo de su abasto en 1763 y 1764 . El gobierno central concedió dicha liberalización para todo el reino durante el último trimestre de 1763. Igualmente, en 1780, decretó una reducción del $15 \%$ en los derechos aduaneros que pagaban las reses vacunas importadas desde Marruecos. A.M.J.F., A.C., cabildos 22-4-1763, f. 100; 5 9-1763, f. 164; 17-2-1764, f. 448; y 24-4-1780, f. 59. Sobre la incidencia de la politica aduanera en los abastos, PALOP, J. M.: Op. Cit., pp. 36-72. 
En ocasiones, se producían en el seno del cabildo municipal fuertes discrepancias sobre si era o no pertinente la compra de trigo. A la discusión normal de valoración de la situación existente, sobre si ésta era extrema o no, se añadía el debate económico, dominado por la perenne insuficiencia de los caudales públicos precisos para sufragar la adquisición. Por ejemplo, la compra de trigo en 1750 se pudo realizar al tomar 120.000 reales del pósito, mientras que en 1793, para adquirir 20.000 fanegas se tuvo que concertar un préstamo de 1.590 .000 reales, afortunadamente sin interés ${ }^{59}$. Casi siempre, detrás de estas controversias, subyace una cuestión de fondo, la competencia que el cabildo municipal, con sus compras, le podía hacer a los comerciantes establecidos en la localidad y que tenían en el comercio de granos un lucrativo negocio ${ }^{61}$. En julio de 1779, con la cosecha recién recolectada, se hizo una proposición para el acopio de trigo ya que se estaba observando como empezaba a subir de precio, situándose entre los 55 y 57 reales la fanega. El diputado del común, D. José de la Puente, se opuso a la compra alegando que no era necesaria, a lo que el veinticuatro D. Pedro de Vargas contestó que le parecía extraña dicha opinión, cuando le constaba que el propio señor de la Puente, comerciante matriculado de granos, había hecho competente provisión. En el mes de septiembre se seguía debatiendo sobre la posible adquisición de trigo, aunque ahora el precio ya alcanzaba los 68 reales. A finales de febrero de 1780 , el veinticuatro D. Pedro de Vargas se quejaba en el cabildo, de que, pese a sus advertencias, no se hubiera hecho la operación de compra, observándose en ese momento una gran carestía, estando el trigo a 94 reales la fanega ${ }^{61}$. Al mismo tiempo, remitía al Consejo de Castilla una representación informándole de como «los diputados del común no han sabido o querido hacer reservas de granos», dejando entrever la responsabilidad interesada de éstos en dicha acción, debido a que «son todos abastecedores, comerciantes de granos y arrendadores de diezmos», acusación que, aunque se enmarca en el enfrentamiento que se daba en Jerez entre cargos perpetuos y electos de su ayuntamiento, no deja de tener un cierto fondo de verdad ${ }^{62}$.

Además de recurrir al aprovisionamiento exterior, las autoridades, para asegurarse el abastecimiento en periodos de escasez, no dudaban en dictar medidas en el sentido de prohibir la salida del término de aquellos productos que consideraba precisos para el avituallamiento de la localidad ${ }^{63}$. Así, contamos con autos en los que se veda, los años

59. Estos recursos extraordinarios debían contar con la autorización expresa de las autoridades centrales. En 1793, el síndico personero viajó personalmente a Madrid para agilizar las gestiones del permiso. A.M.J.F., A.C., cabildo 10-12-1793, f. 245.

60. Un ejemplo, en el año de 1769, los 12 comerciantes de granos matriculados de Jerez introdujeron en la localidad un total de 40.416 fanegas de trigo, que se suman a las 11.341 que habían comprado en el propio término. Destaca el comerciante D. Juan Haurie, pues él solo almacenaba 20.654 fanegas. A.M.J.F., Leg. 178, exp. 5.437

61. La sucesión de hechos en A.M.J.F., A.C., cabildos 23-7-1779, f. 149; 25-9-1779, f. 185; y 28-2-1780, f. 40.

62. Archivo Histórico Nacional, Consejos, Leg. 767.

63. Medida muy habitual en estos casos. Algunos ejemplos en PEREZ SAMPER, M. A.: Art. Cit., p. 417 y ALBEROLA. A.: «Abasto urbano y protesta popular...», p. 336. 
1759,1760 y 1763 , la extracción del pan cocido y, en 1757 , con el fin de afianzar la provisión de las carnicerías públicas, la salida de ganado ${ }^{64}$. Este tipo de disposiciones proteccionistas decae en su uso a partir de 1765 , cuando son emitidas diversas normas sobre la libertad de comercio de granos y otros comestibles. Así, cuando en el mes de abril de 1773 se planteó en el cabildo, ante la escasez existente, la posibilidad de impedir la saca de granos hacia otras localidades, no hubo unanimidad sobre la cuestión, ya que se recordaba, por varios capitulares, la mencionada normativa liberalizadora. Esta legislación, al parecer, se estaba cumpliendo con pulcritud, como lo demuestran los varios expedientes sobre extracción de granos localizados en Jerez, algunos de los cuales coinciden, incluso, con años de cosechas nada favorables ${ }^{65}$.

Otra medida que en estos momentos de escasez y carestía solía aplicarse, con más rigurosidad de la habitual, era la de regular la elaboración del pan y tasar su precio de venta. Estas actuaciones colisionaban frontalmente con los intereses de atahoneros y panaderos, que se oponian a reducir sus márgenes de beneficio. En la penuria de granos de 1785 el cabildo ofreció a los panaderos 5.000 fanegas de trigo al precio de adquisición de 69 reales, con la condición de que la hogaza de pan, de 3 libras, se vendería a 20 cuartos, a lo cual se negaron. Tras arduas negociaciones se permitió la venta, primero, a 21 cuartos y, finalmente, a 23 cuartos. Años más tarde, durante la crisis de 1793, las autoridades municipales procedieron a elaborar un reglamento en el que se regulaba, de forma minuciosa, el número de hogazas que, por fanega de trigo, deberían ofrecer los panaderos según cada una de las cuatro calidades de pan existentes. Del mismo modo, en atención al coste del trigo vigente en ese momento, 84 reales, fijaron el precio de venta de la hogaza de segunda calidad, la más adquirida, en 24 cuartos, permitiendo una subida de un cuarto, por cada cuatro reales en que se encareciera el trigo. En este caso, quizás por la dicha cláusula de revisión, no consta la oposición de los panaderos ${ }^{66}$.

Cuando las adversidades naturales daban lugar a las crisis agrícolas el gobierno local de Jerez solía prestar especial atención a dos colectivos concretos del sector agrario: los labradores y los jornaleros. Las medidas que atañen a los segundos las veremos en el siguiente apartado, por lo que nos centraremos ahora en las medidas económicas y fiscales que intentan mejorar la situación de los agricultores.

En primer lugar, las autoridades locales solían solicitar al gobierno central la reducción o exención en el pago de los impuestos que tenían que abonar los labradores. Así, en 1751 comprobamos como el concejo de Jerez recurría al Intendente para que no se exigiera a los agricultores del término la contribución de paja para el ejército, "en consideración del infeliz estado en que generalmente se hallan todos sus bienes, pues aún para levantar sus agostos y peujales es necesario valerse de nuevo empeño».

64. Datos en A.M.J.F., Histórico reservado, cajón $6, \mathrm{n}^{\circ} 30, \mathrm{ff} .176$ y 109.

65. Estos expedientes, de los años 1756, 1759, 1762, 1768, 1771, 1774, 1780, 1783 y 1789, en A.M.J.F., Leg. 177, exps. 5.409-5.41!; Leg. 179, exps. 5.439-5.443.

66. El reglamento en A.M.J.F., A.C., cabildo 25-2-1793, f. 40. 
En general, las instancias hacendísticas eran muy reacias a estas concesiones, que sólo otorgaban en casos de extrema gravedad y fehacientemente comprobados, como ocurrió en los años 1750 y 1753 , ambos con cosechas perdidas ${ }^{67}$. En algunas ocasiones, la gracia concedida no pasaba de una simple moratoria, casi siempre de un año, para pagar las contribuciones adeudadas al fisco, medida que solía acompañarse con un aplazamiento, por el mismo tiempo, para el pago de las rentas que los labradores arrendatarios debieran a los propietarios de la tierra ${ }^{68}$.

Igualmente, el gobierno local jerezano apoyaba a los agricultores a través del pósito de titularidad municipal, prestando granos no sólo para la siembra, sino también para las faenas de escarda, teniendo en este caso el préstamo como finalidad aportar, en los meses difíciles de marzo a junio, el trigo que se necesitaba para la obligada manutención de los trabajadores ${ }^{69}$. Durante el periodo de 1771-1787 el pósito de la ciudad de Jerez prestó de media anual a los labradores 18.640 fanegas de trigo. Cuando las cosechas eran deficitarias se observa como la devolución no se realiza en los plazos acordados y los impagos se acumulan. De este modo, en 1773 la deuda de los labradores con el pósito se situó en 8.600 fanegas, pero la peor situación se dio entre 1784 y 1786. En la primera anualidad de este nefasto trienio la deuda se situó en 7.871 fanegas, ascendiendo a 11.403 en 1785, para alcanzar la cifra de 17.944 fanegas en 1786. A partir de 1787 la situación empezó a normalizarse, aunque todavía se adeudaban 5.658 fanegas ${ }^{70}$.

Los gestores del pósito, conocedores en todo momento de la dura realidad agrícola, no dudaban en conceder facilidades y moratorias para los pagos. Un ejemplo lo tenemos en 1793, cuando solicitaron al Consejo de Castilla autorización para no exigir de forma inmediata la devolución de los granos prestados, «ya que no cogiéndose y siendo absolutamente imposible la cobranza sólo resultara perjudicar a los labradores sin efecto, y dar mayor valor a los granos», a lo cual el Consejo dio una aprobación condicionada, ya que se debería conceder la moratoria, en proporción, a la fortuna y a la cosecha obtenida por cada uno de los deudores, cuestión que entrañaba una concienzuda pesquisa, motivo por el cual el cabildo de Jerez decidió remitir una nueva representación, lo que venía a significar una moratoria encubierta, dado que ya habían transcurrido cinco meses desde la primera petición ${ }^{71}$.

67. En 1753 se perdonaba a los labradores las dos terceras partes del valor de los conciertos del año 1750 y en 1755 se condonaban las deudas correspondientes al concierto de 1753 , valoradas en 133.068 reales. A.M.J.F., Reales Órdenes, cajón 17-20, n" 68 y cajón 17-18, n" 64. Peticiones y concesiones de rebajas o perdón de impuestos en el ámbito valenciano en ALBEROLA, A.: «La percepción de la catástrofe...», pp. 262-264 y «Abasto urbano y protesta popular...», p. 330.

68. Un ejemplo, referido al año 1753, en A.M.J.F., Reales Órdenes, cajón 17-20, n"67.

69. El papel de los pósitos en las economías agrarias en el trabajo ya clásico de ANES, Gonzalo; «Los pósitos en la España del siglo Xvil», en Economia e «Ilustración» en la España del siglo xill, Madrid, 1969, pp. 7 [-94.

70. Esta información en A.M.J.F., Histórico Reservado, cajón 24, exp. 9

71. A.M.J.F., A.C., cabildos 24-5-1793, ff, 122-126 y 15-10-1793, f. 214. 
Además de no proceder al cobro de las deudas, las autoridades jerezanas ampliaron su ayuda a los labradores en el mal año de 1793, comprando por su cuenta 18.000 fanegas de trigo al objeto de repartirlo para la sementera, al precio tasado de 75 reales la fanega, cuando el valor de mercado estaba entre los 95 y 100 reales, asumiendo el pósito el déficit resultante ${ }^{72}$.

Una ultima medida de apoyo hacia los labradores, aunque no la menos importante, consistía en regular el mercado de trabajo de tal manera que no se excedieran los salarios. Las autoridades locales recurren a este tipo de ordenación de forma especial durante los años de malas cosechas, cuando los agricultores tienen problemas de liquidez y los jornaleros, ante la carestía de los alimentos, pretenden una mayor retribución por las faenas agrícolas. En la colección de edictos y bandos del ayuntamiento de Jerez sólo se localizan, durante la segunda mitad del siglo XVIII, tres autos en los que se dictan normas para fijar el valor de los jornales que deberían percibir los trabajadores del campo. Las dichas disposiciones fueron emitidas los años 1753, 1764 y 1787, el primero de perdida de cosecha, el segundo, aunque de recolección normal, viene precedido de una cosecha catastrófica, mientras que 1787 presenta también una muy deficitaria producción. Los autos establecen que los jornales a pagar cada semana se fijaran la mañana del domingo, concurriendo a la plaza pública para su arreglo sólo y exclusivamente los capataces y labradores, decretando penas pecuniarias y de prisión para los jornaleros que hicieran acto de presencia durante las deliberaciones o que reclamaran aumentos sobre los jornales convenidos ${ }^{73}$. Estaba claro porque grupo socioeconómico se decantaba el cabildo municipal de Jerez, entre cuyos componentes destacan algunos poderosos labradores o familiares de éstos.

\section{III.3. Preservando la paz social}

Cuando ante el azote de determinadas adversidades naturales, tales como la continuidad de temporales o la persistencia de una sequía, las tareas agrícolas no se podían llevar a cabo de forma regular o se suspendían, la mayoría de los jornaleros se quedaban sin trabajo, viéndose forzados a mendigar para obtener de la caridad los alimentos que no podían adquirir por falta de salario. El intendente Olavide recalca este aspecto, como uno de los más destacados de la sociedad rural andaluza, en su conocido informe para la ley agraria:

«No hay cosa tan comin en Andalucía como ver en invierno inundarse las grandes y pequeñas poblaciones de hombres que llaman del campo, que el dia antecedente trabajaban por su jornal, y que al otro día, en que las lluvias impiden las faenas, se acogen al poblado, echándose como enjambres, a pedir limosnas por las calles (...). Estos hombres la mitad del año son jornaleros y la otra mitad mendigos $\rangle^{74}$.

72. La operación contó con la aprobación del Consejo de Castilla. A.M.J.F., A.C.; cabildo 19-12-1793, ff. $248-249$.

73. A.M.J.F., Histórico Reservado, cajón 6, n 30, ff. 31, 336 y 678.

74. El texto recogido por MERCHÁN, A.: La reforma agraria en Andalucia. El primer proyecto legislativo (Pablo de Olavide, Sevilla, 1768), Sevilla, 1996, p. 165. 
En la ciudad de Jerez de la Frontera, debido al gran número de jornaleros existentes, entre 4.000 y $8.000^{75}$, por otra parte todos precisos para su amplísimo término y su diversificada agricultura, el fenómeno descrito se manifestaba con extremada dureza, dando lugar a una compleja problemática a la que debía enfrentarse el gobierno municipal. El paro estacional, en los meses invernales, era una cuestión hasta cierto punto normal, motivada por razones técnicas, entre la siembra y la escarda el cultivo predominante del cereal no necesitaba ninguna otra labor $^{76}$. La anormalidad se producía cuando los agentes meteorológicos, lluvia o sequía, contribuían a dilatar el periodo de paro, impedían realizar actividades alternativas y agudizaban las situaciones de escasez o carestía del trigo.

En Jerez, durante el periodo 1750-1799, la documentación consultada hace referencia a tan sólo ocho años en los que la prolongación del paro estacional o su conjunción con otros factores provocan una situación laboral de crisis. En cinco casos, que corresponden a los años 1763, 1773, 1785, 1786 y 1792, son los temporales de lluvias los que ocasionan la larga paralización de las faenas agrícolas. En los años 1764 y 1793 la suspensión de las labores fue originada por la pertinaz falta de agua. Mientras que en el año 1780 el paro estacional comienza por la demasía de lluvias, pero se dilata por efecto de la sequía. La mayor parte de las anualidades mencionadas coinciden, además, con cosechas deficitarias, lo que aumenta la sensación de precariedad de los trabajadores.

Las autoridades locales, ante la falta de trabajo de los jornaleros, se ven obligados a actuar por dos motivos esenciales. Por un lado, estaría la cuestión moral, que les llevaba a poner en practica medidas caritativas, muy en consonancia con la doctrina cristiana, se trataba de ayudar a sus congéneres más desfavorecidos y necesitados. Y por otro, la responsabilidad de mantener el orden público y la paz social, principios que las ilícitas acciones perpetradas por los jornaleros desocupados ponían en peligro, y para cuyo resguardo se planteaban tanto providencias benéficas como coercitivas. En 1793 , el señor corregidor resumía estos dos aspectos y añadía otra finalidad de carácter práctico, al indicar que el cabildo debía socorrer a los jornaleros «porque son sus vecinos, porque son pobres, porque no declinen en excesos y porque no se extravien a otras provincias dejando a este pueblo sin los precisos trabajadores para cuando llegue el caso de sus faenas». Es decir, se plantea la posible ayuda como un medio para impedir la emigración de unos trabajadores que eran imprescindibles para el sostenimiento de la actividad agrícola de Jere $z^{77}$.

Fuera por caridad cristiana, por mantener la paz pública o por fijar la población laboral, la medida más utilizada fue la de proceder al reparto de limosna, consistiendo

75. Según una encuesta de 1753 habia 4.225 jornaleros, sin incluir los trabajadores fijos del campo. A.M.J.F., A.C., cabildo 6-6-1753, ff. 123-127. En el Censo de 1787 «Floridablanca», Cádiz, se computan 7.752.

76. Aspectos del paro estacional agrario, que se manifiesta incluso en el siglo XX, en BFRNAL, A. M.: La lucha por la tierra..., p. 419 y CALERO, A. M.' Historia del movimiento obrero en Granada (1909-1923), Madrid, 1973, pp. 204-205.

77. A.M.J.F., leg. 331, exp. 9.799. 
ésta, generalmente, en raciones de pan, en concreto una pieza de libra (460 gramos) por trabajador, con independencia del número de personas que compusiera su familia. Las autoridades jerezanas se mostraron siempre bastante reacias a otorgar este tipo de ayudas, tanto es así que, en varias ocasiones, tras haberse aprobado en cabildo y teniendo, incluso, autorización superior, determinaron, finalmente, no proceder a su distribución. La excusa que solía darse era que la situación meteorológica había mejorado, que los trabajadores estaban empleados y, por lo tanto, no había necesidad de dar la limosna ${ }^{78}$. Pero en dicha actitud influían otras razones de mayor peso. Estaba, por supuesto, el problema financiero, el coste que para las arcas municipales o el pósito suponía el sufragar el socorro. La preocupación de los regidores estaba justificada, ya que solfa tratarse de cantidades significativas que ponian en peligro el ya de por sí delicado equilibrio de las cuentas públicas. En 1785 se repartieron, durante un mes, unas 120.000 libras de pan, cada una de las cuales costaba un real. Mientras que, en 1793, el montante de la limosna repartida entre el 11 de marzo y el 19 de abril alcanzó los 114.042 reales $^{79}$.

Y también se sopesaba por las autoridades la posibilidad de que la práctica de la caridad potenciase, precisamente, lo que se quería evitar, la mendicidad callejera, y que llegara a fomentar la conversión de los jornaleros en pedigüeños, provocando una escasez de mano de obra. En esta línea, el veinticuatro marques de Casa Vargas advertía durante un debate en 1785 que...

«se aumenta más la mendicidad cada dia porque con el socorro que se les franquea quizás mucha gente aplicada se arrima al ocio, como ven que por los socorros que se les dispensan no necesitan buscar exquisitos medios para ganar el pan por su trabajo» ${ }^{(0)}$.

Para paliar, en lo posible, esta desviación se empieza a plantear, a partir de 1780 , la pertinencia de vincular la percepción de la limosna a la realización de determinados trabajos de carácter público. Esta nueva forma de entender la beneficencia se estaba fomentando por las autoridades superiores de la monarquía, y tenía como objetivos, combatir la mendicidad, poner en valor el trabajo y facilitar un aumento de la producción $^{\$ 1}$. Las autoridades de Jerez aplicaron este sistema, por vez primera, en el año 1785 , dando ocupación a unos 130 jornaleros en la composición de caminos. En esa misma tarea se emplearon, durante el paro estacional de 1792, unos 180 trabajadores. Y, en la grave crisis de 1793, también para el arreglo de caminos, se pensaba contratar a unos 200 hombres, pero se presentaron hasta 1.500 y uaunque se intento que los sobrantes buscasen otro destino, reunidos todos los operarios dijeron que se irian en hora buena pero que les diesen pan, y al ver esta confisión se determino que siguiese el trabajo»,

\footnotetext{
78. Así ocurrió en 1778 y 1780. Las continuas deliberaciones y el retraso en la ejecución de los acuerdos propiciaban el paso del tiempo y el cambio de la meteorología.

79. A.M.J.F., A.C. 2-4-1785, f. 126 y leg. 331, exp. 9.799. Parte de la ultima cantidad, hasta unos 28.275 reales, se sufragó por donativos de instituciones y particulares.
}

80. A.M.J.F., A.C., cabildo 21-3-1785, ff. 110-114.

81. Las principales disposiciones sobre la materia en Novísima Recopilación..., libro VH, título XXXVII. 
aspecto este último bastante interesante, ya que nos presenta, por un lado, la capacidad de intimidación de los jornaleros y, por otro, la inmediatez de la concesión como mal menor que evite el peligro de asonada o alboroto ${ }^{82}$. De todas formas, la disposición del cabildo municipal para ofrecer trabajo público era muy limitada. Primero, porque no habia ocupación para todos $\mathrm{y}$, segundo, por la sempiterna carencia de fondos de la hacienda local. Al jornalero que, aceptando la oferta municipal, se ponía a trabajar en el arreglo de caminos no se le podía retribuir con sólo una libra de pan, era normal acompañar ésta con un mínimo sueldo que oscilaba entre los 2,5 y los 4 reales, lo cual no deja de representar una limosna, ya que sería la mitad, aproximadamente, de lo que cobraría en las faenas habituales del campo.

Para evitar estas sangrías de las arcas municipales, se propuso por varios capitulares en 1785 la constitución de un montepío cuyos fondos serían los que sufragaran las limosnas y las retribuciones por los trabajos públicos que deberían percibir los jornaleros durante los paros estacionales. La idea, sugestiva en sus objetivos, flaqueaba en aspectos tan determinantes como el de la financiación, abriéndose un extenso debate para discernir de que medios valerse para conseguir los capitales necesarios, puesto que ni siquiera se planteaba, por inviable, contar con aportaciones de los propios trabajadores del campo. Por otro lado, tampoco había acuerdo sobre las ocupaciones que se ofrecerían a los jornaleros a cambio de percibir la ayuda del montepío. Así, se señalaba, que éste era un asunto para meditar, procurando que los trabajos alternativos «no perjudiquen el ejercicio de la agricultura, principal fomento de esta ciudad y aún del Estado, sin que se engrian (los trabajadores) en otra ocupación ni destino más que en el tiempo de la calamidad, que será de un mes en cada año», en definitiva, que no se pusiera en peligro la estructura económica y laboral de la localidad de la que ellos y sus allegados eran los mayores beneficiarios ${ }^{83}$. La cuestión, como es de suponer, quedó aplazada sine die.

Como ya hemos señalado en varias ocasiones, los paros estacionales de los jornaleros por efecto de las adversidades naturales, podían derivar en verdaderos problemas de orden público. Las noticias de falta de ocupación de los trabajadores agrícolas por las lluvias o la sequia van siempre acompañadas de referencias a la formación de cuadrillas para solicitar o exigir limosna y de denuncias sobre actos de pillaje, robos y asaltos. En algunos momentos, la situación alcanzó extremos delicados, como en 1793, según exponía el jurado D. Vicente Ferrer Gil...

"¿admite duda que para socorrer el pueblo de pan le es preciso a los panaderos para conducir las cargas de él a la panadería valerse de tropas para custodiarlas?, ¿admite

82. Los datos en A.M.J.F., A.C., cabildos 26-3-1785, f. 118 y 27-1-1792, f. 47 y leg. 331, cxp. 9.799. ANDRÉS GALLEGO, J.: «Protesta social en la Andalucía del siglo XVIII», en El movimiento obrero en la Historia de Cádiz, Cádiz, 1988, pp. 17-35, señala como las autoridades, ante los alborotos. solían aceptar la reivindicación en todo o en parte. Algo, que por otro lado, estaba terminantemente prohibido, como se recuerda en la Pragmática Sanción por la cual se prescribe el orden con que se ha de proceder contra los que causen bullicios o conmociones populares, Aranjuez, 17-4-1774.

83. Sobre la cuestión del montepío, A.M.J.F., A.C., cabildos 11-4-1785, f. 139 y 6-5-1785, ff. 164-169. 
duda que no se puede salir del pueblo con ningún pan, ni otros comestibles para el socorro de los ganaderos porque abanderizados ya los trabajadores en grandes cuadrillas acometen a los que los conducen y no contentos con llevarse el pan y demás los maltratan?, ¿admite duda que al golpe de la oración no se puede salir de las casas por no sufrir los repetidos insultos hechos a muchos vecinos y particularmente a muchos capitulares",

argumentos con los que quería evitar, aunque sin éxito, la decisión tomada por sus compañeros de corporación de dar por finalizadas las ayudas a los jornaleros en paro ${ }^{84}$.

Cuando, por estos motivos, la paz y el orden social peligraban, las autoridades locales no dudaban en poner en ejecución medidas coercitivas. En un primer nivel se procedía a la promulgación de bandos y edictos en los que se prohibían determinadas prácticas consideradas delictivas o, al menos, perniciosas. Así, se limitaba cualquier tipo de concentración en lugares públicos; se vedaba la formación de cuadrillas para solicitar limosna, concretándose que se entendía por cuadrilla todo grupo compuesto por más de dos individuos; $y$, por supuesto, se condenaba la coacción y el uso de actitudes violentas. Los infractores de estas normas serían considerados vagabundos, apresados y remitidos a los arsenales reales para cumplir trabajos forzosos ${ }^{85}$.

Pero si la situación empeoraba o para precaver tumultos, se solía solicitar al Capitán General de Andalucía, que residía en la vecina localidad de El Puerto de Santa María, el envío de algún contingente de tropa que colaborara con las rondas de la ciudad en el mantenimiento de la seguridad ciudadana y en la persecución de aquellos que se habían convertido en malhechores y se refugiaban en las sierras colindantes.

Como hemos podido apreciar, las consecuencias de las adversidades naturales sobre la anquilosada sociedad y economía agraria del siglo XVII son significativas, tanto en su complejidad como en su intensidad. La problemática a que dan lugar afecta desde sectores concretos, como labradores y jornaleros, hasta el conjunto de la sociedad, que sufre crisis de subsistencias por las deficitarias cosechas. El papel en este escenario de las autoridades locales se muestra esencial, ya que ante la presencia diferida del gobierno central, son ellas las que deben actuar, poniendo en práctica medidas que abarcan un amplio campo de acción. Hay que preservar el orden público, favorecer el sosiego espiritual, asegurar el abastecimiento y ayudar a los colectivos más damnificados. Todo un reto, de cuya resolución favorable depende, no sólo el atenuar los efectos de las calamidades, sino la propia justificación y consolidación de los componentes del gobierno local como elite política y social.

84. A.M.J.F., A.C., cabildo 16-4-1793, ff. 92-96.

85. Ejemplos de estos edictos en A.M.J.F., Histórico Reservado, cajón 6, n 30, ff. 284 y 351. 